\title{
Notas sobre el comportamiento ante un sismo de los edificios históricos con estructura de mampostería Definición de la regola dell'arte' en las construcciones murarias y su identificación en la edificación histórica
}

Francesco Piccarreta Fiorani

Università degli Studi di Roma La Sapienza, Italia Recibido: 27 de septiembre de 2015 / Aprobado: 5 de octubre de 2015

\begin{abstract}
Se describe el comportamiento estructural de las construcciones históricas de mampostería, las características de la construcción según la regola dell'arte y la actitud antisísmica de las mismas. Se realiza un registro de la constitución y estado de conservación y unas verificaciones "expeditivas" basadas en los criterios de cálculo. Surge en el artículo la definición del proyecto de consolidación, basado en el conjunto de técnicas de intervención dotadas de requisitos específicos: la aplicación de los procedimientos para la comprobación de la seguridad como se indica en la normativa y un análisis de los efectos del terremoto en el área de la ciudad italiana de L'Aquila.
\end{abstract}

terremoto, edificios históricos, mampostería, lesiones, consolidación antisísmica

\section{Notes on the Behavior of Historic Buildings with Masonry Structure in an Earthquake. Defining the regola dell'arte in Masonry Buildings and their Identification Within the Historic Building}

This article describes the structural behavior of historic masonry buildings, the construction characteristics according to regola dell'arte, and the antiseismic attitude of these constructions. Within this article there is also a record of the structure and conservation condition of constructions, as well as some "prompt" checks based on the criteria of calculation. The article shows a consolidation project definition based on a set of intervention techniques provided by specific requirements such as the application of procedures for checking safety conditions as outlined in regulations, and an analysis on the earthquake effects within the Italian city of L'Aquila.

earthquake, historic building, masonry, injuries, seismic reinforcement

1 El término regola dell'arte define las prácticas constructivas originadas en el Medioevo, que normaban la utilización de materiales, instrumentos, procedimientos y soluciones constructivas en el ámbito de los gremios profesionales. Las especificaciones técnicas que eran consideradas de uso común lograban un estándar técnico en la arquitectura histórica [NdE]. 
El antiguo constructor de obras de mampostería poseía, bien definidas y establecidas, las reglas de la buena ejecución, fuere en el empleo de los materiales o en la modalidad de obrar; reglas que, sin embargo, debían ser compatibles con diversas exigencias, a veces apremiantes y con frecuencia en neto contraste. Exigencias, por ejemplo, constituidas por las costumbres locales (la tradición), por el apuro de concluir la construcción, por la disponibilidad local -del tipo, calidad, dimensión- de los materiales a emplear, de las exigencias económicas en conjunto, que resultaban especialmente apremiantes para edificaciones de modesta importancia.

Como resultado de estas exigencias opuestas, la obra realizada con frecuencia tenía que afrontar algún evento extraordinario (temido, pero no siempre considerado), como la manifestación de un sismo en un territorio más o menos extenso, pero sin embargo siempre vasto.

Hoy, con la tradición constructiva con la que contamos, se puede identificar la edificación según la regla del arte, aquella en la cual confiar como una segura protección frente al sismo. Lo afirmado no resulta inmediata ni seguramente identificable en la sola consulta de los manuales técnicos (especialmente en aquellos publicados entre fines del siglo XVIII y las primeras décadas del XIX), sino que debe ser confiado a un levantamiento crítico de la construcción, y a la comparación con los mandatos de la tradición de la construcción documentada.

Por lo tanto se trata de realizar un levantamiento cuidadoso que utilice las capacidades de observación y de interpretación por parte del especialista a cargo, además de las pruebas instrumentales sobre los elementos de construcción. Por ejemplo, en lo que respecta a posición, tamaño y correspondencia de las paredes opuestas de los anclajes de las cadenas eventualmente existentes; fisuras a lo largo de los ángulos de los muros, que manifestar; distancias entre las paredes; constitución y consistencia de la mampostería; posición de los espacios-puerta (o ventana) existentes; etcétera.

Por los elementos de la construcción que escapan a la observación directa -como las paredes recubiertas de estuco-, puede ofrecer indicaciones útiles sobre la composición y las eventuales faltas de homogeneidad de construcción, incluso sobre la presencia de un patrón de fisuras que denuncie 
la discontinuidad o falta de homogeneidad del tejido de la mampostería subyacente. Un ejemplo de particular evidencia se muestra en la foto de la figura 1, que se refiere a una prueba de ensayo de eliminación del estucado en la fachada de un edificio del centro histórico de L'Aquila, afectado por el terremoto del 2009.

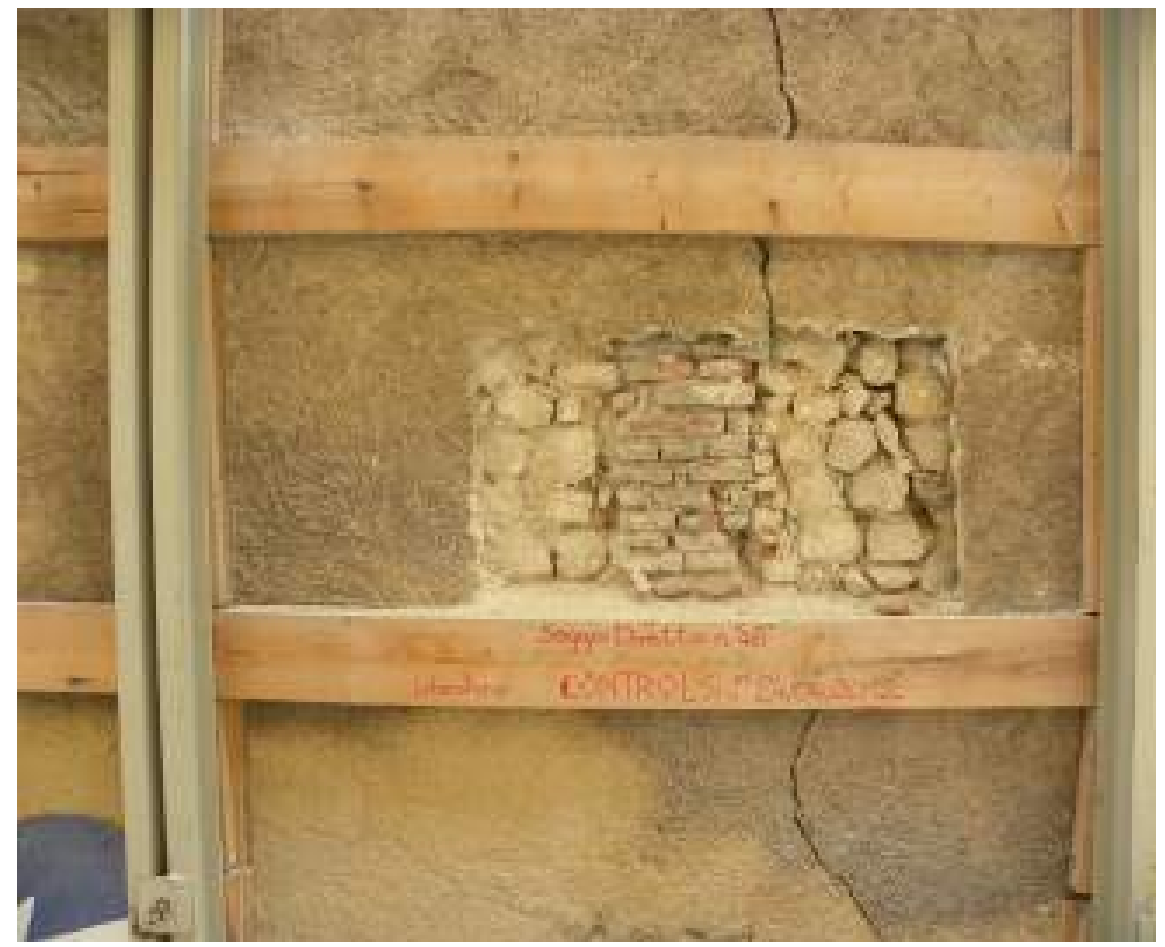

Figura 1.

La prueba ha confirmado la presencia, debajo del estucado, de una vistosa discontinuidad en el cuerpo de la construcción de la pared, ya sugerida por la presencia de una amplia lesión vertical. En la construcción diseñada con piedras de pequeñas o medianas dimensiones, resulta añadido un bloque de ladrillos sólidos - mal o para nada sujetos a la mampostería originaria-, con el fin de rellenar un vacío existente. 
Durante siglos, la humanidad ha tenido que sufrir las consecuencias terribles de los terremotos - considerados, a la par que las calamidades naturales, una manifestación de la ira divina-, de los cuales ha conservado la memoria a manera de "catálogos", los que refieren la localidad, la época y la descripción (aproximada) de los efectos producidos. Las pinturas y decoraciones reproducen, de manera ingenua y fantástica contemporáneamente, las destrucciones y los daños producidos en la edificación de ciudades con almenas y torreones; imágenes que fijan establemente en el tiempo los efectos desarrollados en pocos segundos y amplificados por el terror y la fantasía.

Solamente después del terremoto de Lisboa de 1755, la emergencia postsísmica en el área europea fue afrontada en términos científicos. Fueron, en esa ocasión, puestas a punto las primeras normas antisísmicas para las nuevas construcciones, sintéticamente basadas en:

- estructura (de madera) de edificios de mampostería;

- límites de altura de las edificaciones;

- el ancho mínimo de las calles;

con disposiciones que, por largo tiempo, hicieron "escuela" en la Europa de la "tierra tremolante", y en particular en Italia ${ }^{2}$. El gobierno napolitano, por ejemplo, en 1784 predispuso un reglamento para la edilicia en zona sísmica, luego del terremoto que en el año precedente había destruido Calabria. Las normas fueron redactadas en línea con las correspondientes colocadas en Lisboa, y codificaron, en particular, el recurso al sistema de construcción

2 Precedentemente, disposiciones antisísmicas (sustancialmente, las últimas dos arriba indicadas) ya habían sido reportadas en un documento normativo del gobierno siciliano el 28 de junio de 1694, para reconstruir la ciudad de Catania, afectada por el terremoto en 1693.

En la Italia anterior a la unificación -y luego, en el Estado unificado entre fines del siglo XIX y principios del XX-, las normas se sucedieron con trágica continuidad, siguiendo el criterio de las disposiciones específicas para las localidades afectadas por el terremoto; disposiciones, por lo tanto, siempre posteriores a una manifestación sísmica y frecuentemente referidas a las técnicas de edificación y a la disponibilidad de materiales específicos en el lugar considerado. Por otro lado, en las zonas históricamente sísmicas, los reglamentos locales y las tradiciones de edificación habían introducido -para las nuevas construcciones- las principales reglas del arte, con el fin de exorcizar las manifestaciones de daños por sismos de intensidad "usual". 
denominado encofrado, que había dado buen resultado tanto en Lisboa como, sucesivamente, en otras zonas de las regiones meridionales de Italia. De fácil y rápida ejecución, consistía en un armazón espacial de madera, constituido por montantes, vigas, diagonales, cuyo entretejido era recubierto por la mampostería; una evolución, por lo tanto, de la opus craticium romana y de las construcciones de Europa del Norte.

Por ello, la tradición de la edificación documentada resulta de los decretos legislativos subsiguientes, en el arco temporal de alrededor de doscientos cincuenta años (desde 1694 a la primera década del siglo XX), y se basa en la observación de los daños sufridos por los edificios a consecuencia de las manifestaciones sísmicas. Las prescripciones técnicas resultantes son expresadas como reglas de construcción, en términos de consistencia $\mathrm{y}$ de proporciones que se deben conferir a las partes constructivas de las edificaciones a ser realizadas.

Asume, por tanto, una fisonomía propia el denominado edificio según la regla del arte, es decir, aquel que garantiza - por medio de una correcta concepción, una apropiada ejecución y una atenta conservación de la obrala adecuada resistencia ante las acciones sísmicas, al menos hasta un nivel de intensidad suficientemente elevado. Se trata de previsiones de la construcción consistentes en poner en obra:

- construcciones compactas y de adecuado espesor, dispuestas "en enrejado" en las dos direcciones, y no muy distantes entre sí, bien sujetas recíprocamente a lo largo de los ángulos;

- arquitrabados de madera sobre todas las aberturas practicadas en los muros, por un largo conveniente;

- durmientes de madera o de piedra incorporados en la mampostería, en la cima de los muros con vigas de soporte;

- conexión o amarres de las paredes de mampostería con cadenas de fierro o de madera;

- conexión de las vigas de la techumbre a los muros;

- apuntalamiento de mamposterías contrapuestas (arcos) entre edificios adyacentes; 
- entrepisos abovedados solamente en el plano del sótano;

- perfilado continuo de refuerzo de los muros de la fachada o dispuestos en contrafuerte;

- alturas limitadas en general.

En conjunto con reparaciones "coser y descoser" de porciones de mampostería, acompañadas eventualmente con demoliciones dirigidas a la reducción de la altura total o a la eliminación de elementos de entrepisos de empuje, las disposiciones indicadas también constituían el patrimonio de intervención para reparar los daños por el sismo y reforzar las edificaciones existentes.

En la relación entre la proposición normativa y la observación de los daños, con frecuencia se notan modificaciones, sustituciones y, a menudo, reinserciones de disposiciones, en una continua búsqueda encaminada a obtener el máximo resultado en términos de seguridad. En el cuadro cronológicocomparativo $^{3}$ de la tabla I, están nombradas las reglas de construcción difundidas en la cultura antisísmica de la época para la reparación de los edificios dañados por los terremotos, y ahí son evidenciadas las sucesivas confirmaciones y variaciones. Los "sí" indican la referencia explícita a la regla específica. Resulta ser una confirmación para algunas técnicas que han permanecido continuamente en vigor, y que vienen a constituir el conjunto de aquellas técnicas tradicionales que hoy concentran en sí mismas los aspectos de la economía, de la confianza, de la mínima capacidad invasiva $\mathrm{y}$, frecuentemente, de la reversibilidad ${ }^{4}$.

Se observa que la alternancia de confirmaciones y revocaciones a través del tiempo -detectables en la tabla I-, de los dispositivos individuales nombrados, puede representar los acontecimientos de las construcciones afectadas por un sismo, reparadas y reforzadas, sucesivamente expuestas a un nuevo sismo, el cual "comprueba" el comportamiento confirmando o no la eficacia de los refuerzos dispuestos.

3 Reproducido de L. Boscotrecase y F. Piccarreta (2009). Edifici in muratura in zona sismica [Edificios de mampostería en zona sísmica]. Palermo: Flaccovio Editore.

4 Este último término se debe interpretar tal como es especificado más adelante. 
Tabla I.

\begin{tabular}{|c|c|c|c|c|c|c|c|c|c|c|}
\hline \multirow{2}{*}{\multicolumn{2}{|c|}{$\begin{array}{c}\text { Dispositivos antisísmicos } \\
\text { especificados } \\
1694\end{array}$}} & \multicolumn{9}{|c|}{ Comunicación de entrada en vigor de las normas } \\
\hline & & \multirow{2}{*}{$\begin{array}{c}1784 \\
\text { no }\end{array}$} & \multirow{2}{*}{$\begin{array}{r}1859 \\
\text { sí }\end{array}$} & \multirow{2}{*}{$\begin{array}{c}1884 \\
\text { sí }\end{array}$} & \multirow{2}{*}{\begin{tabular}{|c|}
1887 \\
sí
\end{tabular}} & \multirow{2}{*}{\begin{tabular}{|c|}
1906 \\
no
\end{tabular}} & \multirow{2}{*}{1909} & \multirow{2}{*}{1935} & \multirow{2}{*}{$\begin{array}{c}1962 \\
\text { sí }\end{array}$} & \multirow[b]{2}{*}{ sí } \\
\hline \multirow{8}{*}{$\begin{array}{c}\text { Dispositivos } \\
\text { encontrados } \\
\text { en las } \\
\text { fuentes } \\
\text { de archivo }\end{array}$} & $\begin{array}{l}\text { 1) Cadenas de fierro } \\
\text { para eliminar el empuje } \\
\text { en las bóvedas y arcos. }\end{array}$ & & & & & & & & & \\
\hline & $\begin{array}{l}\text { 2) Sustitución de } \\
\text { las bóvedas con } \\
\text { techumbre. }\end{array}$ & no & no & sí & sí & sí & sí & sí & sí & sí \\
\hline & $\begin{array}{l}\text { 3) Cadenas de fierro } \\
\text { para entrelazar } \\
\text { construcciones } \\
\text { dañadas, o con función } \\
\text { de abrazadera. }\end{array}$ & no & sí & no & no & no & sí & sí & sí & sí \\
\hline & $\begin{array}{l}\text { 4) Espuelas murales } \\
\text { o con formación "de } \\
\text { refuerzo". }\end{array}$ & no & no & sí & no & no & no & no & no & no \\
\hline & 5) Arcos de contraste. & no & no & no & no & no & no & $(*)$ & $(*)$ & $\left({ }^{*}\right)$ \\
\hline & $\begin{array}{l}\text { 6) Reparación de } \\
\text { mampostería dañada } \\
\text { mediante "coser y } \\
\text { descoser". } \\
\end{array}$ & no & no & no & no & no & sí & sí & sí & sí \\
\hline & $\begin{array}{l}\text { 7) Indicaciones sobre } \\
\text { las modalidades de } \\
\text { ejecución de las obras } \\
\text { según la regla del arte } \\
\left({ }^{* *}\right) .\end{array}$ & no & no & sí & sí & sí & sí & sí & sí & sí \\
\hline & $\begin{array}{l}\text { 8) Sustitución de los } \\
\text { techos con empuje. }\end{array}$ & no & no & sí & no & sí & sí & sí & sí & sí \\
\hline \multirow{4}{*}{$\begin{array}{c}\text { Dispositivos } \\
\text { no } \\
\text { encontrados } \\
\text { en las } \\
\text { fuentes } \\
\text { de archivo }\end{array}$} & $\begin{array}{l}\text { 9) Demolición de pisos } \\
\text { altos. }\end{array}$ & no & no & no & no & no & no & sí & sí & no \\
\hline & $\begin{array}{l}\text { 10) Sustitución de } \\
\text { las escaleras de } \\
\text { mampostería o voladizas. }\end{array}$ & no & no & no & no & no & sí & sí & sí & sí \\
\hline & $\begin{array}{l}\text { 11) Reducción de las } \\
\text { proyecciones. }\end{array}$ & no & sí & no & no & no & sí & sí & sí & sí \\
\hline & 12) Enjaulado del edificio. & no & no & no & no & no & no & sí & sí & sí \\
\hline
\end{tabular}

(*) La norma prohíbe expresamente los arcos para apuntalar o entrelazar muros.

$\left.{ }^{* *}\right)$ Aun si no constituye una verdadera disposición antisísmica, esta indicación es relevante en la prevención de daños relacionados con los sismos. 
No es diferente a cuanto se verifica -en nuestros días- para las confirmaciones y revocaciones referidas, esta vez, a técnicas de refuerzo "innovadoras"; de emisión más o menos reciente en la producción para la edilicia, pero desprovistas de una suficiente confiabilidad para una prolongada duración en el ejercicio -o en todo caso, por la incorrecta ejecución o definición del proyecto-, o que también se muestran desprovistas de los requisitos requeridos para las intervenciones sobre el patrimonio constructivo histórico-artístico ${ }^{5}$.

Con el mismo fin de identificar la construcción según la regla del arte, pueden ser dirigidas las clasificaciones de los terremotos ocurridos en el tiempo. Efectivamente, la intensidad de un terremoto puede ser hoy definida por el registro de los efectos producidos sobre el medioambiente terrestre (las construcciones, las especies arbóreas, los lugares, las personas), o por las mediciones sismológicas proporcionadas por los instrumentos específicamente instalados. El registro de los daños producidos -principalmente en las construcciones- constituye el método tradicional utilizado y que ha obrado sobre un "tejido" que se ha mantenido largo tiempo homogéneo y después gradualmente se ha modificado (de las construcciones tradicionales de mampostería, a la edilicia de proporciones y construcciones modernas); método que ha llevado a la definición de escalas macrosísmicas, de las cuales la más empleada es la escala de Mercalli, en una de las dos versiones modificadas:

- Mercalli-Cancani-Sieberg (MCS), empleada en Europa.

- Mercalli modificada (MM), empleada en los Estados Unidos.

Ambas versiones están organizadas en doce grados de severidad, relativos a los efectos producidos sobre las personas, objetos, edificios, medio ambiente. Resulta, por otro lado, que una clasificación basada en la identidad de los efectos producidos solo puede ser "subjetiva" en cuanto está basada en los efectos psicológicos, influenciada por los tipos de construcción y por el juicio del especialista. En cambio, una clasificación de este tipo resulta hoy oportuna, porque permite efectuar comparaciones con acontecimientos anteriores e incluso antiguos, en cuanto realizados con procedimientos del mismo tipo.

5 Connotaciones 0 atributos, definidos y nombrados a continuación. 
A continuación, en la tabla II, escala de intensidad MCS, se resumen los términos relacionados con los daños en los edificios. De hecho, los grados del I al V se refieren esencialmente a efectos en las personas, en objetos colgantes, en la vegetación, etc., mientras que el grado XII se refiere a macroefectos en el ambiente.

Tabla II.

Escala MCS (síntesis)

\section{Grado Efectos en las edificaciones}

$\mathrm{VI}$

Casas aisladas y sólidamente construidas sufren daños ligeros; fisuras en el estucado; caídas del revestimiento de techos y paredes. Daños más fuertes, sin ser todavía perniciosos, se encuentran en los edificios mal construidos.

VII Daños moderados en numerosos edificios de estructura fuerte: fisuras en los muros, caen pedazos bastante grandes de enlucido y del estucado, a veces ladrillos, las casas se abren. Las casas mal construidas o reparadas a veces se desploman.

VIII Casi la cuarta parte de las casas queda gravemente dañada; algunas se desploman; muchas quedan inhabitables.

IX Casi la mitad de las casas de piedra se destruyen; muchas se desploman; la mayoría queda inhabitable. Las casas con armazón son arrancadas de sus fundamentos y caen.

X G G Gavísima destrucción de casi tres cuartos de los edificios; la mayor parte se desploma. Incluso las construcciones sólidas de madera y los puentes sufren graves lesiones, algunos se destruyen.

XI Se desploman todos los edificios de mampostería, solamente las construcciones y las cabañas de madera encajada a presión, de gran elasticidad, todavía permanecen en pie. Incluso los puentes más grandes y seguros se desploman a causa de la caída de las pilastras de piedra o porque ceden aquellos de fierro. 
Se observa que:

- Elpatrimonio construido es sustancialmente de mampostería,eventualmente en la variante con armazón (el fierro aparece en los puentes).

- Se identifican los dos extremos del producto construido según la regla del arte (aquí, indicado con la adjetivación sólido o sólidamente construido) y el edificio mal construido, probablemente producto de una cultura y una técnica de confección local (acá, simbolizado por las casas de piedra). El límite de resistencia de esta última se puede colocar entre el grado VII y VIII de la escala, mientras que el límite de resistencia de una construcción según la regla del arte se puede colocar entre el grado IX y X.

En cuanto a la definición instrumental de la intensidad de un terremoto, la grandeza representativa es la magnitud ${ }^{6}$, cuyos valores representativos, también en relación con los valores de la escala macrosísmica, pueden ser encuadrados como se indica en la tabla III siguiente.

Tabla III.

\begin{tabular}{|ll|}
\hline \multicolumn{1}{|c|}{ Magnitud } & \multicolumn{1}{c}{ Sismo } \\
2 & Sacudidas muy débiles \\
De 4 a 4,5 & Daños a estructuras poco resistentes (grado VI) \\
$>6$ & Destructivo \\
\hline
\end{tabular}

En términos de magnitud, el edificio, según la regla del arte, se puede colocar alrededor del valor 6. Para el terremoto en el territorio de L'Aquila (2009), el valor reportado ha sido par a 5,9.

6 Medida de la energía mecánica E producida en el origen (epicentro). También la evaluación de la intensidad por medio de la magnitud -o sea, por medio de la determinación instrumental- no está completamente libre de influencias subjetivas. 


\section{TRANSFERENCIA CUALITATIVA Y CUANTITATIVA DE LA REGOLA DELL'ARTE EN LA ACTITUD DE LA RESISTENCIA A LOS TERREMOTOS: CONFIABILIDAD SÍSMICA}

La solicitada presencia, en la construcción según la regla del arte, de los muros (compactos y de espesor congruente) dispuestos en retículo hace que la acción del sismo -en su componente horizontal, cualquiera sea su orientación- arremeta el cuerpo mural de las paredes de la edificación según dos disposiciones diversas:

- paredes orientadas con el propio plano medio paralelo al sismo (dirección longitudinal);

- paredes orientadas con el propio plano medio perpendicular al sismo (dirección transversal).

Estas, según se presentan, en la dirección de la acción sísmica, con la menor de las dos dimensiones de la sección de la base: el espesor, $t$; las primeras, en cambio, se presentan con la dimensión mayor, B. A las segundas por lo tanto corresponden, en el colapso bajo un sismo, movimientos de volcadura; a las primeras les corresponde en cambio un colapso por agotamiento de la resistencia, que puede manifestarse con dos diversas modalidades: por desplazamiento, que desencadena lesiones diagonales; o por presión deformante, que desencadena lesiones por compresión en un borde de la sección de la base y ruptura en el borde opuesto; indicativamente, las dos modalidades se verifican en los dos casos de sección larga o de sección estrecha, respectivamente. Los entrepisos presentes en los diferentes planos siguen los acontecimientos de las paredes sobre las cuales están establecidos.

El buen montaje recíproco de las paredes a lo largo de los ángulos murales ${ }^{7}$, la presencia de cadenas metálicas (o de madera) de anclaje, la conexión de las vigas de la techumbre y de la cobertura en las paredes, la eventual presencia -solo en el sótano- de un diafragma que contenga empujes

7 Un ejemplo de una ejecución confiable de los refuerzos angulares, se muestra en la foto de la figura 2, que se refiere a una construcción de L'Aquila. La estructura del encuentro angular es de bloques de piedra escuadrada de grandes dimensiones. En segundo plano son visibles los desprendimientos en el plano de cobertura de la edificación contigua. 
horizontales, constituyen elementos de sujeción de las paredes transversales a las longitudinales: en esta situación, es a estas últimas que viene confiada la resistencia al sismo de toda la construcción.

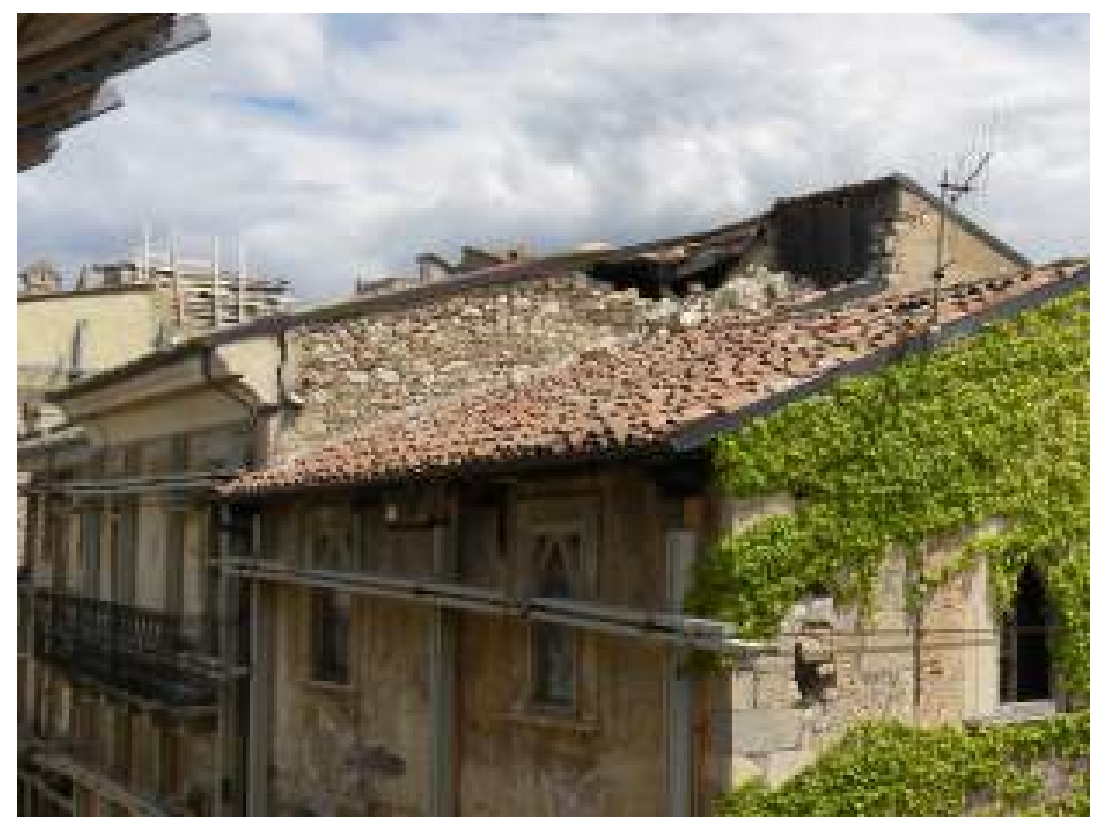

Figura 2.

Una insuficiencia en las conexiones vistas determina por tanto posibles colapsos de carácter local, por desplome de las paredes (transversales), con un eventual compromiso de los entrepisos; una insuficiencia dimensional o de construcción de las secciones de la base determina, viceversa, un posible colapso de carácter total, por agotamiento de la resistencia en todas las paredes.

En definitiva, se puede concluir que es generalmente desestimable la resistencia al sismo de las paredes puestas perpendicularmente al propio plano medio (crisis de desplome) mientras es sensible la resistencia de las paredes coplanares (crisis de deslizamiento/compresión). Aquellas, por tanto, deben ser conectadas a estas de modo de poder utilizar la resistencia para fines de 
la propia estabilidad; estas, todavía, deben poseer dimensiones y constitución tales de impedir el desencadenamiento del colapso global de la construcción. En otros términos: estas son las características principales de la confiabilidad antisísmica del edificio según la regla del arte.

Bajo este punto de vista, son imputables de delito las paredes de fachadas de iglesias o de palacios nobiliarios: de confección y constitución más minuciosas $-\mathrm{y}$, por tanto, de mayor costo respecto de las otras paredes (con frecuencia, de construcción modesta)-, o también que resultan de restauraciones en época sucesiva a la construcción originaria, por tanto con escaso (o ningún) acoplamiento a las otras paredes que han permanecido en su lugar.

Un ejemplo de esto es mostrado en las imágenes de las figuras 3 y 4 , que se refieren a un edificio sacro -actualmente destinado a ser auditorio del conservatorio de música de la ciudad de L'Aquila- después del sismo de abril de 2009. La fachada -en bloques de piedra escuadrada regularmente dispuestos, con bordes en piedra de corte, tímidamente conectados a las paredes posteriores longitudinales- se presenta en incipiente estado de desplome, señalado por las lesiones de separación que la recorren en toda su altura, con amplitud creciente de abajo hacia $\operatorname{arriba}^{8}$, probablemente amplificando un daño precedente, más leve. Se observa fácilmente la notable diferencia de constitución entre la fachada y la pared longitudinal, así como la (consiguiente) falta de conexión entre las dos paredes.

Siempre a la capital de L'Aquila se refieren las imágenes de las dos figuras sucesivas (5 y 6), que reproducen la fachada y una perspectiva lateral de la iglesia del Perpetuo Suffragio (o de las “Ánimas Santas") en la plaza del Duomo, esta también después del sismo del 2009. En las imágenes, el edificio ya ha sido sometido a intervenciones de resguardo, por parte de los bomberos; que ya han sido realizadas para la fachada, y en curso de ejecución para el tambor superior del presbiterio. La fachada, en condiciones de desplome incipiente, ha sido autoanclada a las paredes longitudinales

8 La abertura creciente de abajo hacia arriba caracteriza las lesiones generadas por desplome y las distingue respecto a las de otros orígenes.

9 En modo tal de "desvincularse", sea de los edificios limítrofes, sea del mismo terreno de apoyo (por tanto, sin apuntalados externos). 
mediante dos robustas vigas de contraste en madera laminada y parejas de tirantes perimetrales que la atraviesan, en correspondencia con las dos celdas de los campanarios, y que circundan el interior del edificio sacro con las dos ventanas laterales más lejanas.

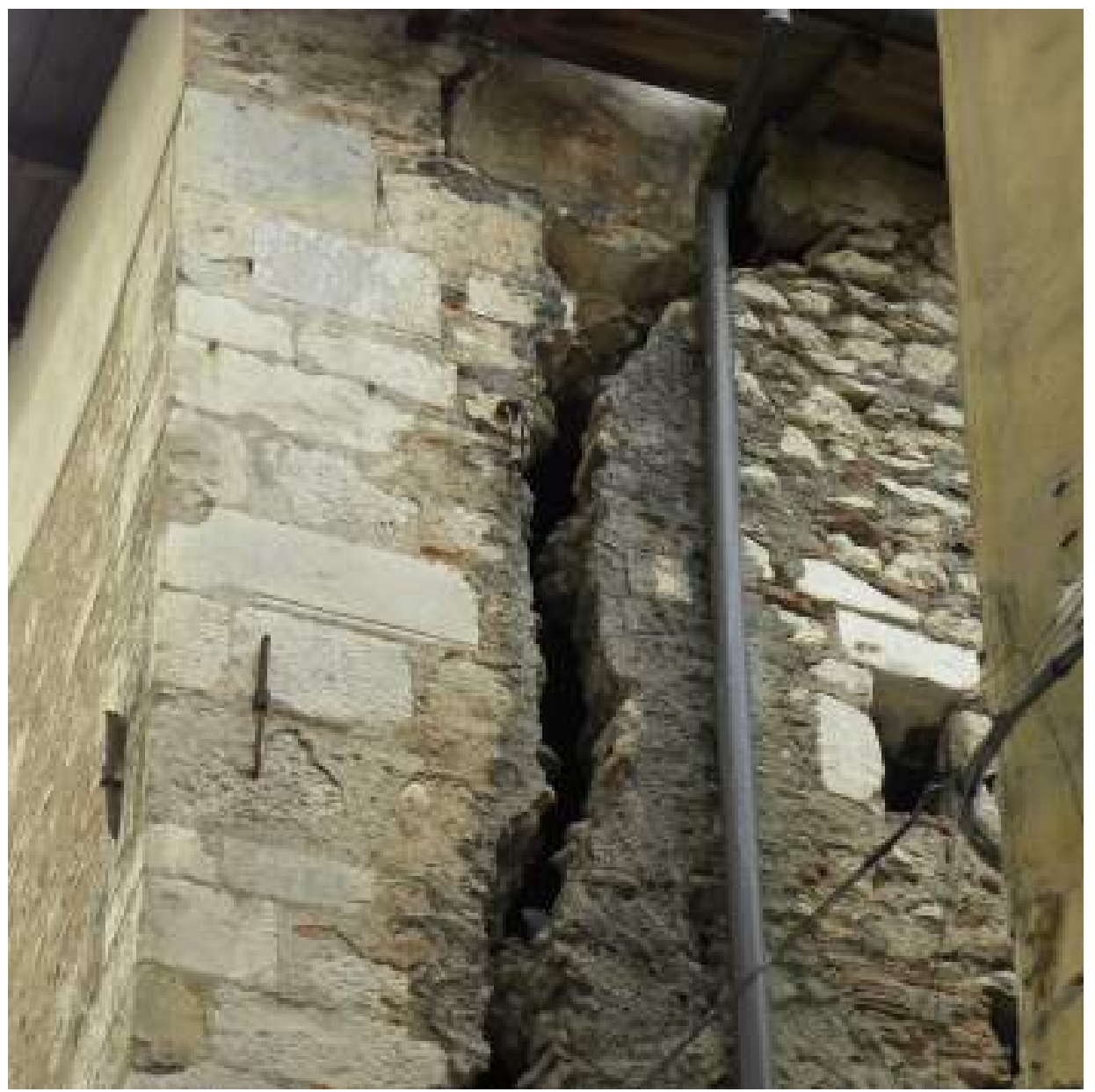

Figura 3. 


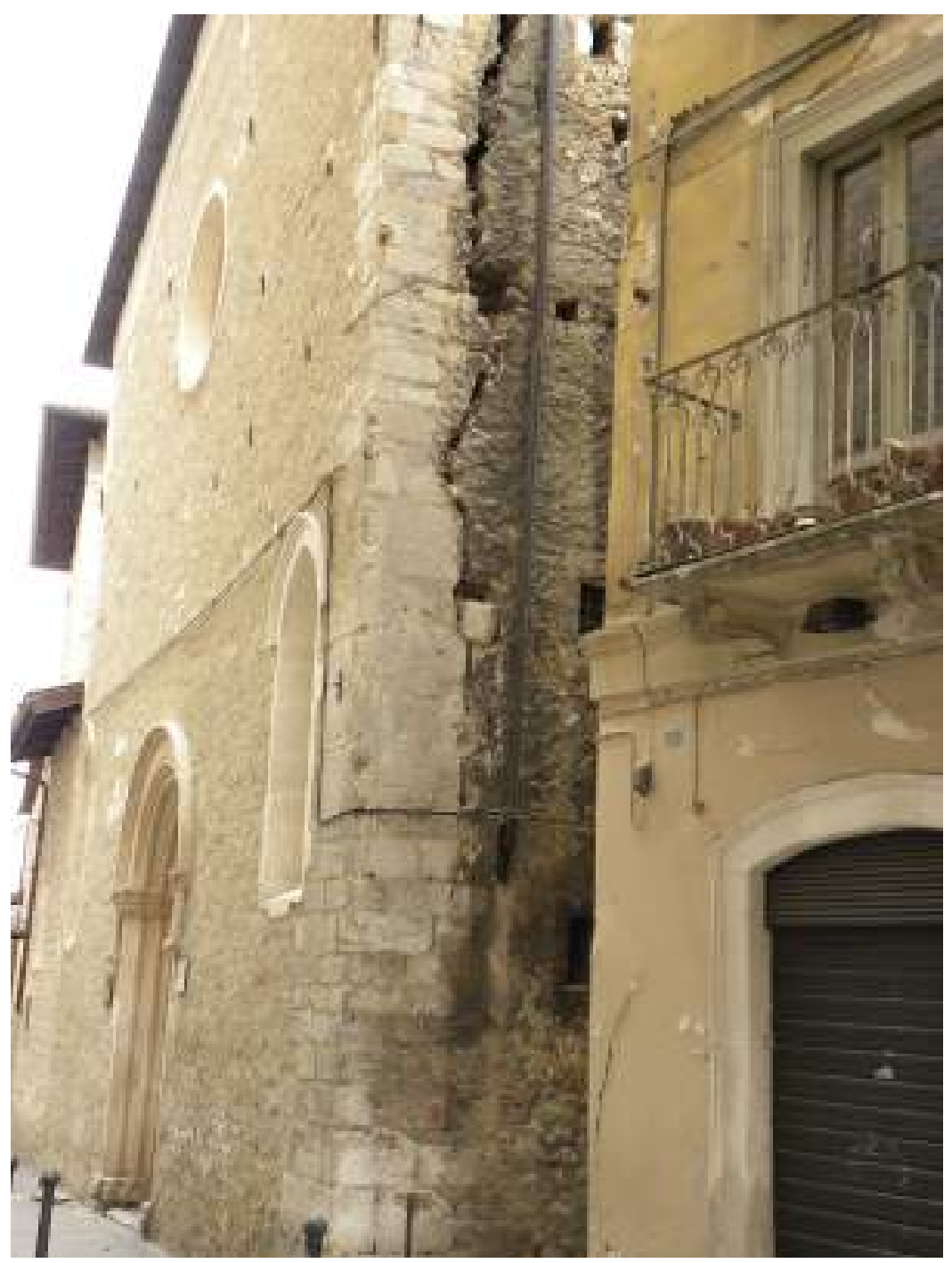

Figura 4. 


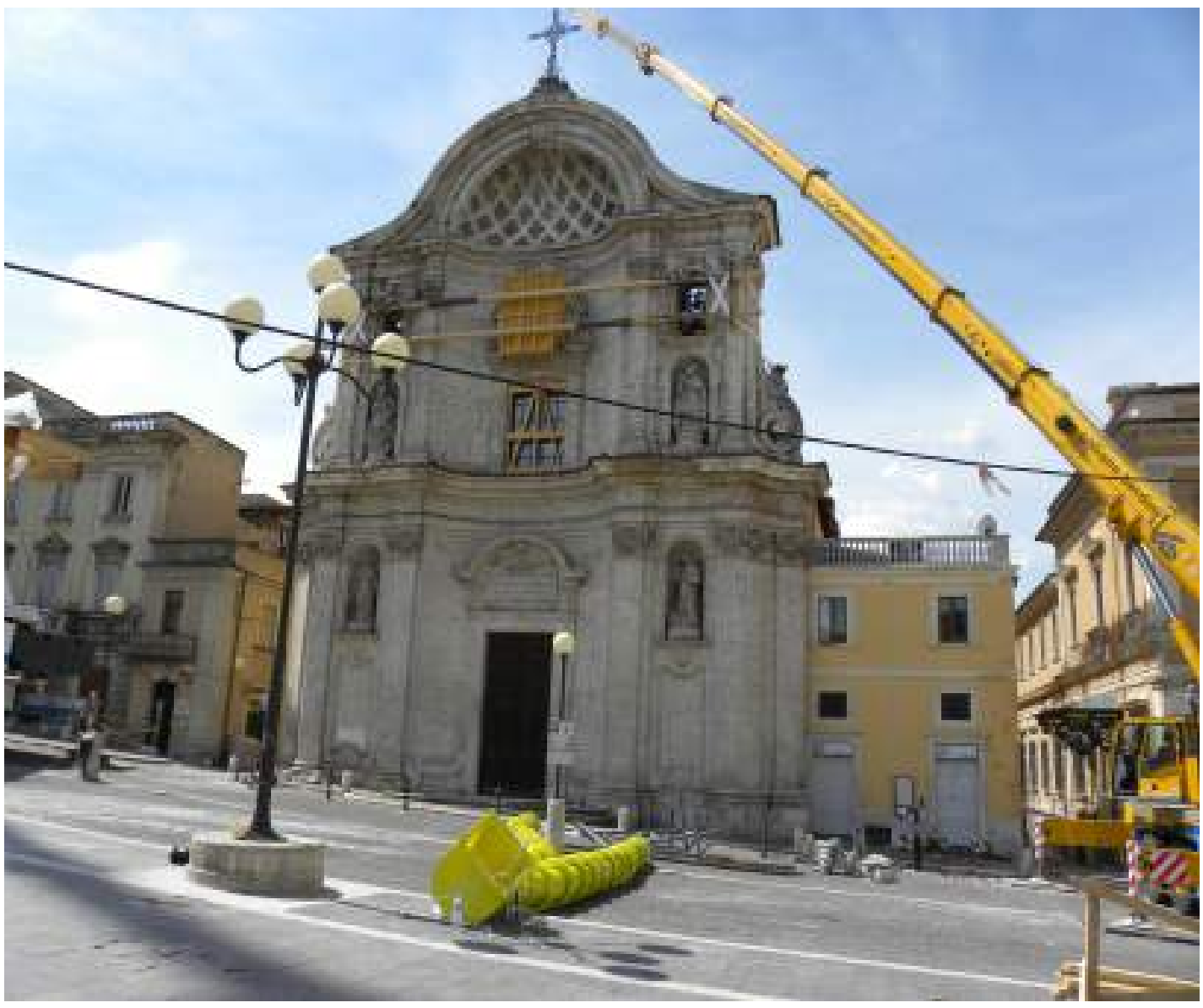

Figura 5. 


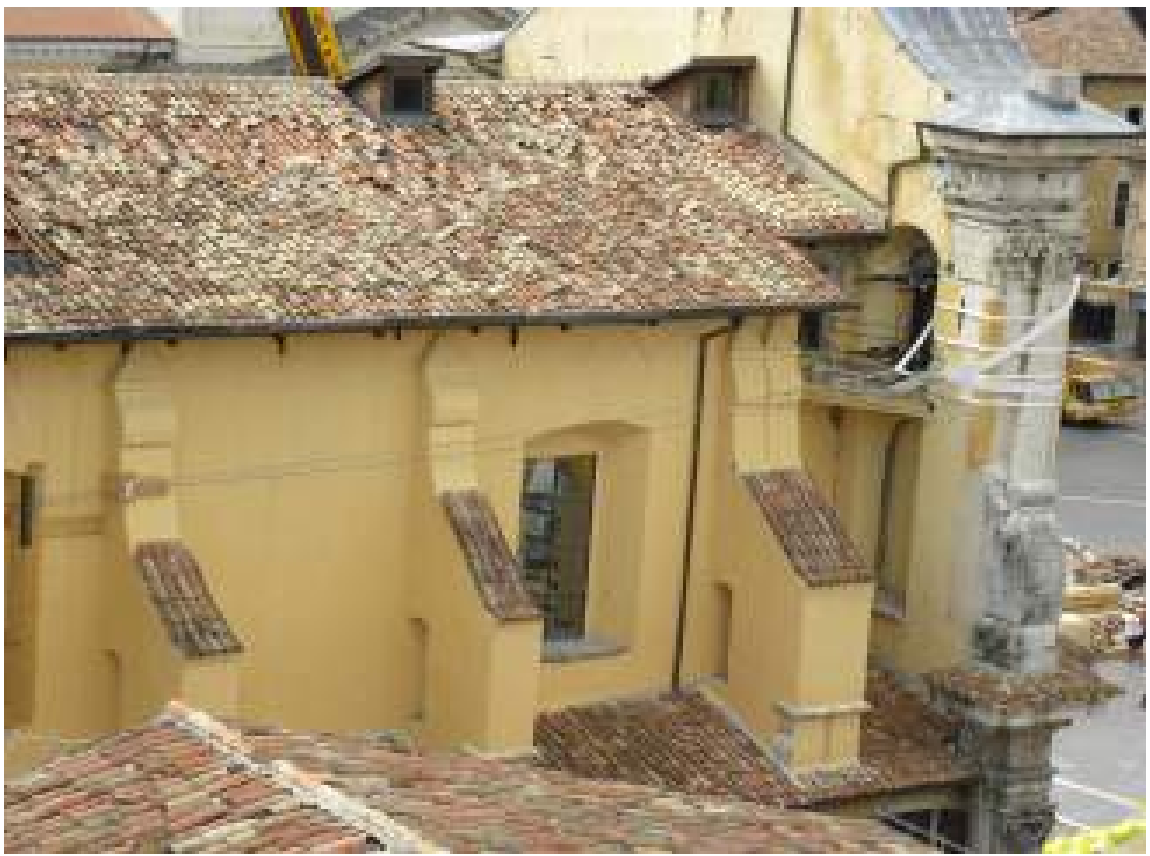

Figura 6.

También en este caso, la fachada aparece desconectada de las paredes del muro posterior y las cadenas presentes -distinguibles por los anclajes a las paredes- parecen dirigidas a la "monoliticidad" de las angulaciones y no a una oportuna conexión con las paredes posteriores de la fachada.

Por lo que respecta a las paredes afectadas longitudinalmente por el sismo (o sea, paralelamente al plano medio), el estudio orgánico del comportamiento bajo la acción de fuerzas horizontales variables en el tiempo (régimen dinámico $)^{10}$ ha proporcionado una serie de relaciones semiempíricas que

10 Desarrollado a partir de los primeros años de la década de los setenta, en los laboratorios universitarios de la entonces Yugoslavia, procediendo por vía experimental mediante pruebas sobre paneles murarios (elementos paralelepípedos con una dimensión, el espesor del panel, más pequeña que las otras dos); continuado luego durante todos los años de la década de los ochenta, en Italia y en otros estados. 
definen la resistencia a las acciones horizontales del sismo. Esta depende de una serie de parámetros constituidos por:

- resistencia al desplazamiento bajo las acciones cíclicas horizontales y resistencia a la compresión, propias de la tipología específica mural empleada, favorables cuanto más elevadas sean;

- estado de compresión (valor medio en la sección) bajo las cargas estáticas de ejercicio, favorable cuanto más elevado sea;

- dimensiones de las secciones de la base.

Se derivan las siguientes posibles estrategias, dirigidas a aumentar el valor de las acciones de colapso:

- Mejoramiento constitutivo por medio de inyecciones de argamasas con aditivos en el cuerpo mural, o reconstrucciones locales de coserdescoser (incremento de los valores de resistencia).

- Tensionamiento en el plano vertical, que obra un incremento del estado de compresión vertical.

- Tensionamiento en el plano horizontal, que se opone al deslizamiento por medio de una compresión horizontal.

- Cerramiento de los vanos con nueva construcción conectada a la existente o conectada con pórticos metálicos (aumento de la sección resistente).

Sobre la base de lo expuesto anteriormente, se distinguen, por tanto, para una pared sujeta a fuerzas horizontales coplanares con la pared misma, dos posibilidades de prevenir el colapso: una corresponde a la rotura por deslizamiento y la otra a la rotura por compresión, en general con dos valores diversos de la fuerza horizontal de colapso: F' ' y F" ${ }_{u}$. El valor límite $F_{u}$ de la fuerza horizontal agente es obviamente el menor de los dos indicados $-\mathrm{O}$ sea, el primero que se manifiesta, en una hipotética progresión de valores crecientes para F, a partir del valor nulo-, y el mecanismo de rotura que se manifiesta es aquel que le corresponde.

Desde el punto de vista numérico, los dos valores de la fuerza de colapso pueden ser determinados mediante expresiones de naturaleza teórica y experimental. 
Indicadas con $\mathrm{fm}_{\mathrm{m}} \mathrm{y}$ con $\tau_{0}$ las resistencias propias de la mampostería en examen -respectivamente a la compresión y el deslizamiento-, y con $\sigma_{0}$ la compresión media en la sección mural (par a la relación entre la carga vertical $\mathrm{P}$ agente y el área de base de la pared, $\mathrm{A}=\mathrm{t} \mathrm{B})$, se tiene:

$$
\begin{aligned}
& \mathrm{F}_{\mathrm{u}}=\tau_{0}\left(1+20 \sigma_{0} / \mathrm{fm}_{\mathrm{m}}\right)^{1 / 2} \\
& \mathrm{~F}^{\prime}{ }_{\mathrm{u}}=\mathrm{A} \sigma_{0}\left(1-1,33 \sigma_{0} / \mathrm{f}_{\mathrm{m}}\right) /(\mathrm{H} / \mathrm{B})
\end{aligned}
$$

Los valores numéricos de las resistencias $\tau_{0} \mathrm{y} \mathrm{f}_{\mathrm{m}}$ pueden derivar de pruebas instrumentales in situ, o también de la literatura; el valor se deriva del análisis de las cargas (véase a continuación).

Las dos expresiones arriba reportadas ponen en evidencia el rol de la "delgadez" H/B de las paredes y de la "cuota de carga" $\sigma_{0} / \mathrm{f}_{\mathrm{m}}$ : al contrario de la delgadez, los valores elevados de la cuota de carga aumentan la resistencia.

Por cuanto concierne a las paredes golpeadas por el sismo transversal, o sea perpendicularmente al propio plano, las modalidades de colapso consisten -como ya fue descrito- en el desplome hacia el exterior ${ }^{11}$, e involucran esencialmente las paredes de la fachada. Estas paredes se "anclan" a las longitudinales, transfiriendo a estas las acciones relativas al peso propio y de los entrepisos eventualmente soportados ${ }^{12}$.

El desplome se puede manifestar en la pared que se separa de las longitudinales a lo largo del acoplamiento (ensamblajes deficientes, regresar a los ejemplos de las figuras 3 a 6), o también puede comportar el arrastre de las cuñas casi triangulares $^{13}$ de las paredes longitudinales, figura 7 . El agarre a la base, la inclinación y la terminación en la parte superior dependen sea de la calidad del entrelazado de la mampostería, sea de la presencia de espacios o de

11 El eje de desplome, en la primera aproximación, está localizado en el borde externo de la sección de la base.

12 Es negativa la presencia de bóvedas murales implantadas en las paredes, sea por el mayor peso que las caracteriza respecto a los techos planos, sea, sobre todo, por la fuerza que conlleva la conformación curva.

13 En este caso, las lesiones de desplome en el conjunto presentan una tendencia inclinada, pero, a diferencia de la lesión por desplazamiento, muestran una amplitud creciente de abajo hacia arriba. 
entradas (estas últimas a menudo no observables desde el exterior, ya que son efectuadas en la cara interna de la pared); a modo de ejemplo, en la figura 8 siguiente se reporta la vista de un cuño de desplome en la pared de la fachada lateral de una construcción en L'Aquila. El encuentro angular está realizado con bloques bien escuadrados; la lesión inclinada parte de la intersección con la pared de la fachada frontal, siguiendo primero los recorridos entre los bloques, luego prosiguiendo hacia la ventana en el altillo, con amplitud creciente desde la base hasta la parte superior. Nótese luego la presencia de las dos cadenas en el ángulo, al nivel del primer piso, empotradas en el espesor de la pared y probablemente poco prolongadas en el cuerpo mural: ineficaces contra el movimiento de desplome.

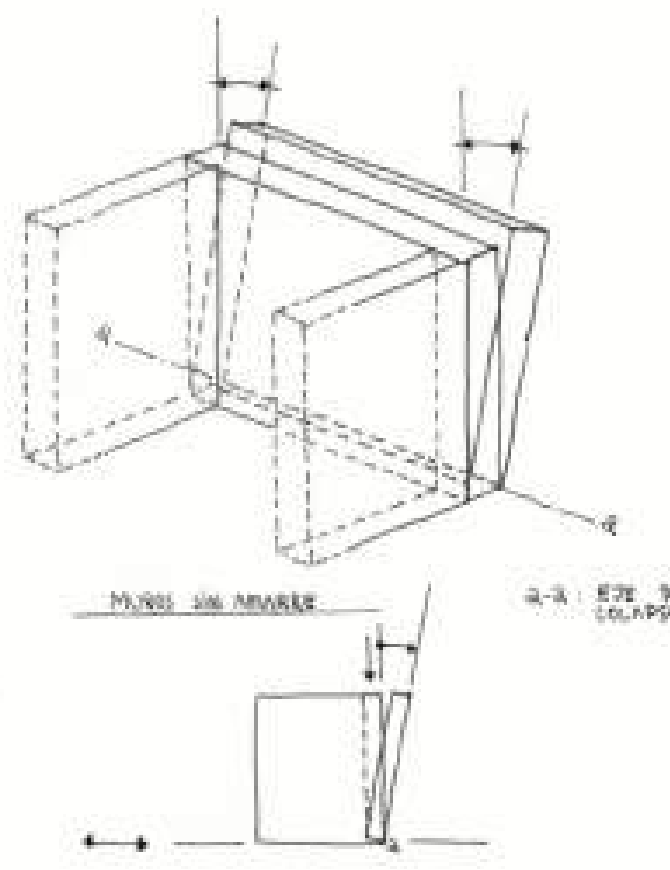

Figura 7.

Fuente: Francesco Piccarreta. Apunte: Abel del Pino

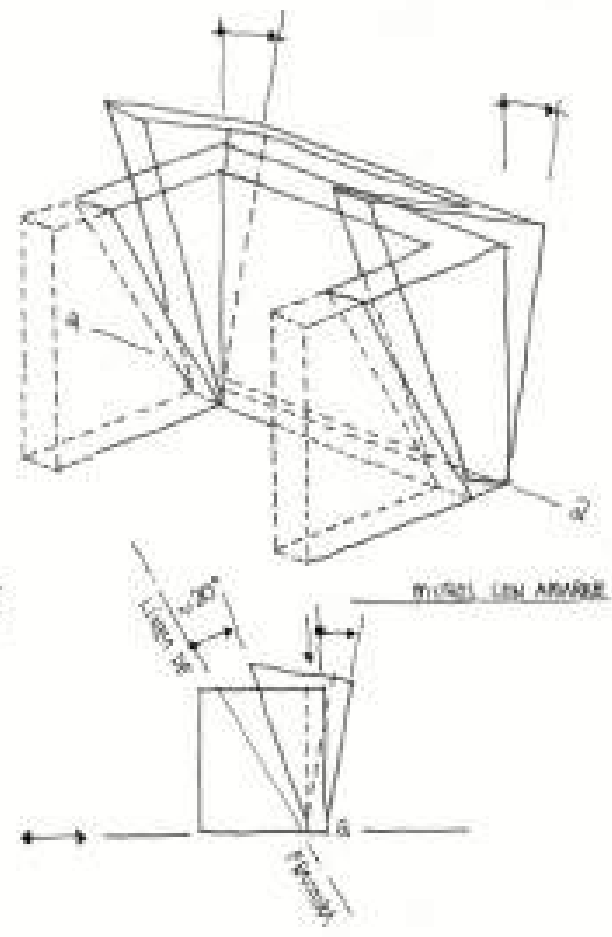




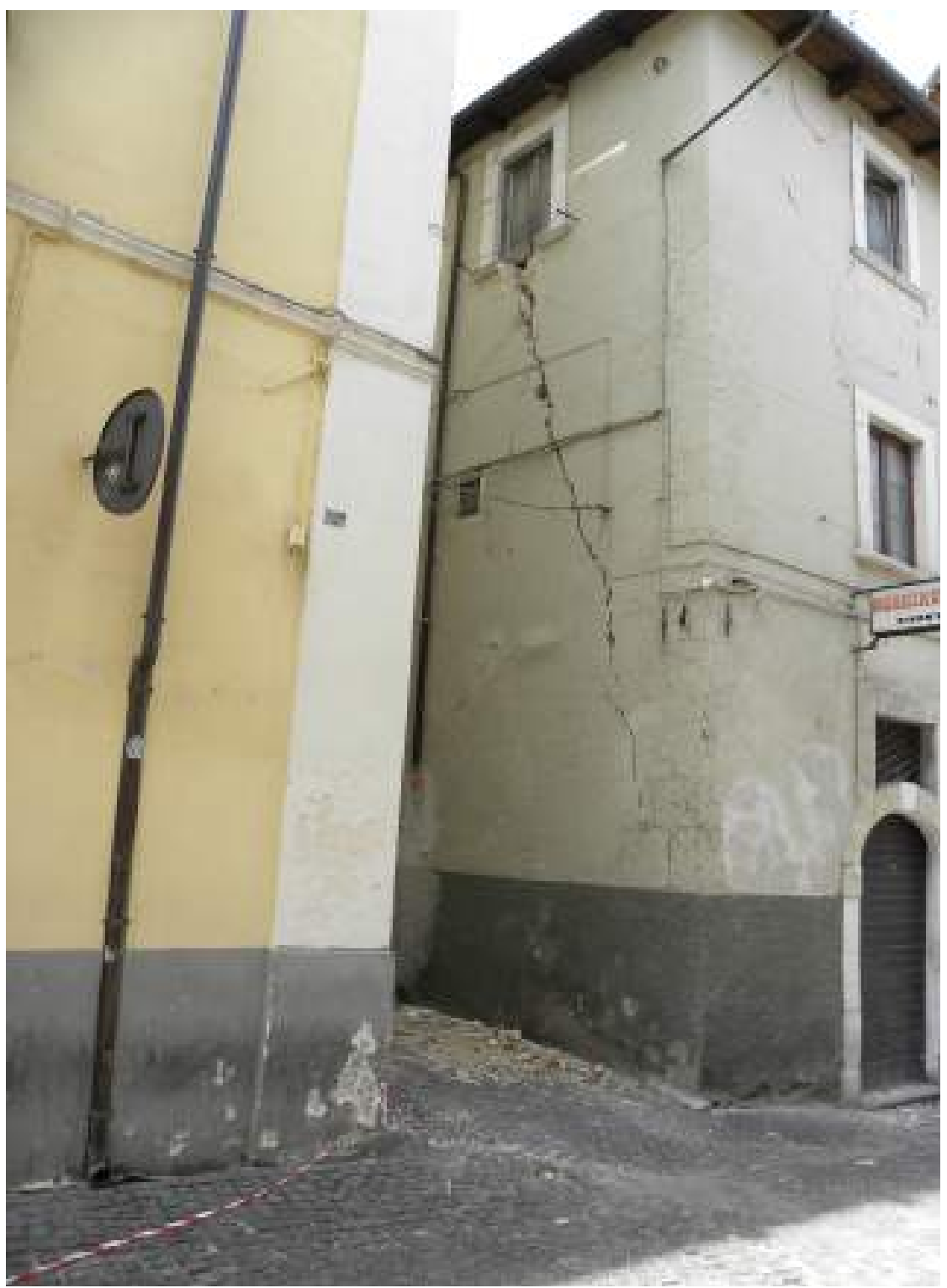

Figura 8. 
El desplome de una pared no sujetada está fuertemente influenciado por la presencia de tirantes y de ganchos eficientemente dispuestos a varias alturas y variadamente anclados a la pared en estudio. Se pueden presentar las siguientes situaciones diversas:

- Pared aislada, o sea, totalmente desprovista de acciones de contraste al desplome que no estén constituidas por el propio peso; la pared se desploma rígidamente respecto del propio borde de base, y el valor de colapso de la fuerza, que es la causa, resulta de carácter limitado; esencialmente, depende de las relaciones entre el espesor y la altura de las paredes y entre el peso de la cobertura y el peso de la pared.

- Pared con retención en la parte superior, constituida por un armazón de cobertura empalmada, en las dos extremidades, a la pared en examen y a la pared contrapuesta (pensada exenta de crisis); en el desplome, la pared se subdivide en dos partes: la inferior, rota respecto a la esquina de base, y la superior, rota en el sentido opuesto, levantándose un poco. El valor de colapso del impulso es sensiblemente mayor que el del precedente (un poco más del doble).

- Pared con retención intermedia, constituida por un tirante puesto a media altura entre las dos paredes contrapuestas; la pared se subdivide todavía en dos partes, diferentes, sin embargo, respecto del caso precedente, con un mayor incremento del valor de colapso del impulso (más de 2,5 veces respecto del primer caso).

- Pared con doble retención, de remate e intermedio; la pared se subdivide en tres partes: la superior se traslada apartándose hacia arriba, las dos de abajo rotan en sentido contrario una respecto de la otra; el valor de colapso del impulso aumenta ulteriormente respecto al primer caso (más de tres veces).

En términos de aumento de las prestaciones antisísmicas de una construcción existente, se evidencia la eficacia general del acordonamiento mural (armado) del remate, de las cadenas en posición intermedia (ancladas con placas de contraste en las dos extremidades), de las perforaciones (armadas) selladas con argamasas tratadas, a lo largo de las esquinas. En cuanto a estas últimas, los esquemas de la figura 7 muestran -en el caso de un correcto aseguramiento 
entre las paredes- la utilidad de proceder con perforaciones armadas inclinadas para unir las dos paredes en la zona baja de la edificación y de implantar bordes armados en la zona del remate en toda la expansión de la pared.

Igualmente eficaz puede resultar "rigidizar" los planos horizontales de modo tal que se pueda establecer una posible retribución de las acciones sísmicas entre las varias paredes golpeadas por el sismo en el mismo plano medio.

\section{EL TERREMOTO DEL 2009 EN EL TERRITORIO DE L'AQUILA}

La ciudad de L'Aquila, capital de una de las regiones centromeridionales de Italia, surge sobre el declive de una colina situada en la hendidura de un valle en cuyo fondo discurre el río Aterno, que constituye el elemento hidrográfico principal del área. El centro histórico de la ciudad está, por tanto, caracterizado por un trazado vial que presenta fuertes desniveles e irregularidades; desde el punto de vista urbanístico, lo construido está caracterizado por la presencia de numerosas edificaciones sacras y de edificios nobles, alternados a una edilicia de construcciones modestas en la parte más baja del centro urbano y a una edilicia más relevante en la parte alta (dominada por la imponente mole del castillo del siglo XVI).

El modelo geológico y estratigráfico del suelo está caracterizado -bajo un manto superficial superpuesto- por un sedimento detrítico limo-arcilloso de color rojizo (los fangos rojos de las colinas de L'Aquila), por una profundidad de alrededor de diez metros, y más abajo de un sedimento de terrenos granulares constituidos por cascajo arenoso, a su vez profundo por más de treinta metros. En el sedimento limo-arcilloso se empalman los cimientos, generalmente poco profundos, de las construcciones y edificios.

El área entera presenta una sismicidad histórica acertada, habiendo estado sujeta a numerosos terremotos y padecido graves daños en 1315 y en 1461, y una casi completa destrucción en 1703. El terremoto de abril de 2009 ha causado numerosas víctimas y producido extensos y generalizados desplomes en la parte más baja del centro urbano; en el tejido edilicio de la parte más alta se han manifestado graves desprendimientos -con el derrumbe de porciones individuales- en los edificios sacros, y daños extendidos y desplomes locales en la edilicia habitacional. La acción coordinada de la Protección Civil, con 
sus derivaciones operativas - primeros, entre todos, los bomberos de toda Italia-, ha logrado rápidamente asegurar todas las edificaciones mediante la inserción de tirantes de acero entre las fachadas contrapuestas, la disposición de apuntalamientos verticales para sostener los entrepisos al interior de las edificaciones, y refuerzos de madera en los vanos de las ventanas y puertas. Se han excluido los apuntalamientos de las paredes en contraste con el plano de la calle y los apuntalamientos en contraste entre edificios sustituidos, justamente, por tirantes en acero que pasan al interior de las construcciones. En la iglesia del Perpetuo Suffragio - que acá se asume como representativa de la edilicia sacra de L'Aquila-, además del aseguramiento de la fachada principal, ha sido realizado un sistema de "prótesis" provisionales mediante el sistema tamborcúpula $^{14}$, compuestas por un amarre externo con tirantes de acero, puestos en tensión luego de su implantación desde lo alto de un entrelazado metálico "tipo paraguas"; este último introducido cerrado al interior del tambor, y abierto en contraste concluida la inserción. En la figura 9 se muestra la fase del amarre externo del tambor.

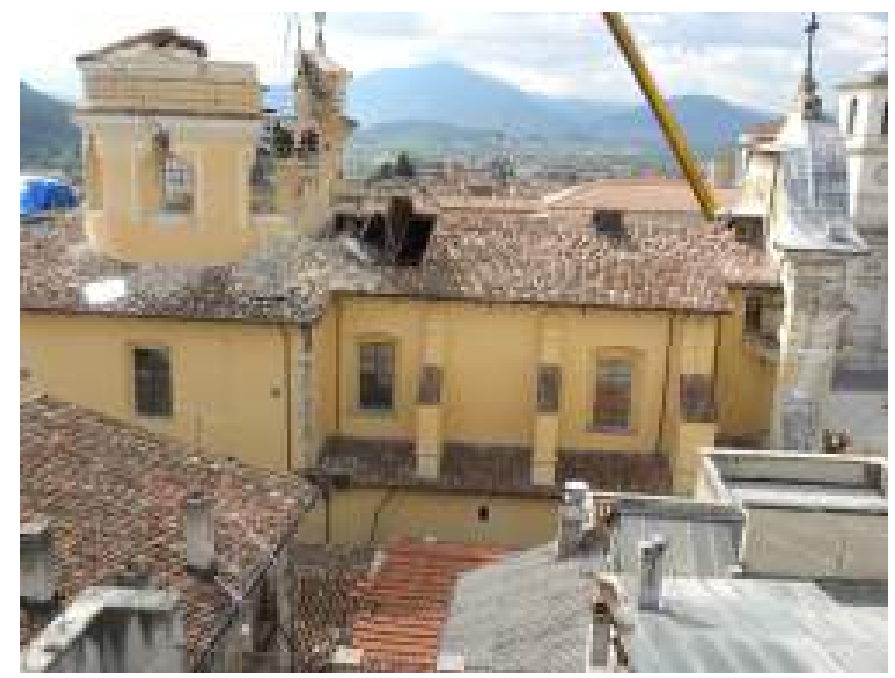

Figura 9.

14 Debidos al arquitecto romano Giuseppe Valadier y realizados en 1805. 
Los mecanismos de colapso más frecuentemente encontrados en las edificaciones del centro histórico consisten en la formación de cinemáticas de volcadura de las paredes de la fachada, con frecuencia acompañadas de la caída de elementos horizontales. Eso, como consecuencia de las tipologías de construcción adoptadas que han recurrido ampliamente a las bóvedas (decoradas) puestas como cielorraso o con viguetas y pequeñas bóvedas muy rebajadas ${ }^{15}$ y también decorativas.

Son frecuentes también los derrumbes parciales en el remate de las paredes, con el consiguiente desplazamiento de las estructuras de cobertura que ahí se apoyan (figuras 10 y 11). Igualmente frecuentes, todavía, son las expulsiones o la fractura de estípites y de arquitrabes lapidarias del siglo XVIII, en los espacios de las ventanas o de las puertas de ingreso.

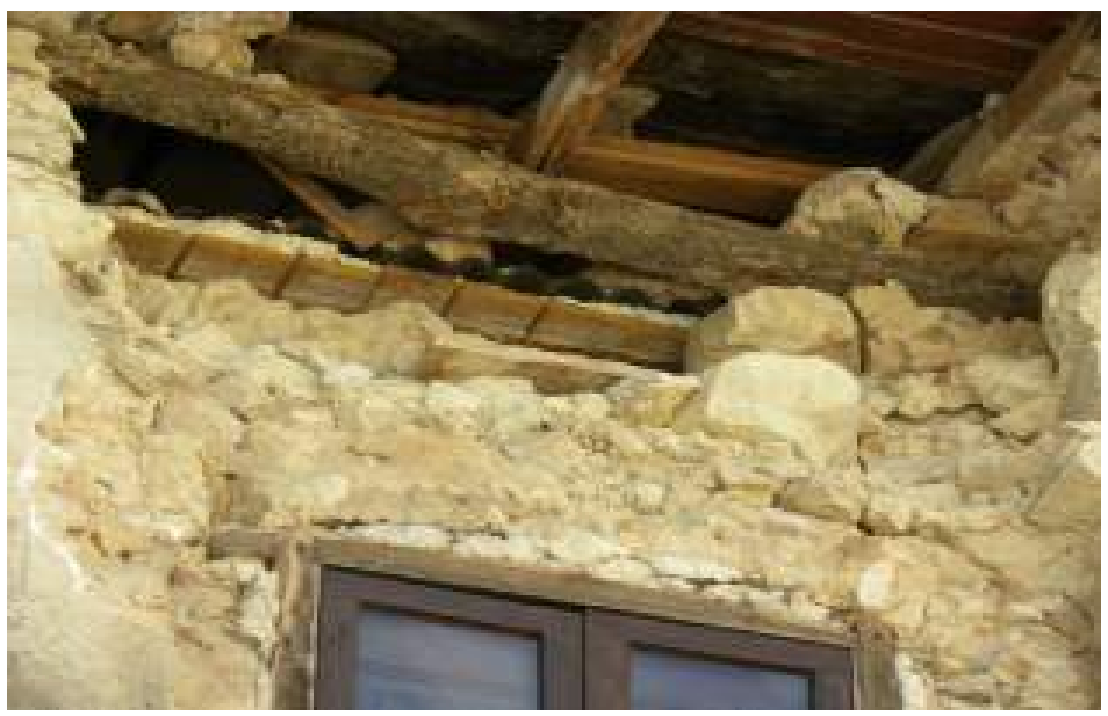

Figura 10.

15 Los cielorrasos tipo bóveda consisten en bóvedas murales de pabellón construidas con ladrillos puestos en folio, por tanto de modesto espesor, implantados con poco cuidado en las paredes perimetrales que las deben sostener, y no siempre dotadas de cadenas de retención. 
Los cielorrasos de viguetas y pequeñas bóvedas están constituidos por ondas paralelas de pequeñas bóvedas murales de ladrillos en folio; cada pareja de ondas contiguas está sostenida al borde del ala inferior por una viga metálica de doble $\mathrm{T}$, mientras que las dos ondas perimetrales están puestas a lo largo de un borde directamente sobre la pared contigua (con la evidente intención de economizar, siendo bastante alto el costo de las viguetas metálicas), con las mismas modalidades descritas para las bóvedas de pabellón. En estas condiciones, las bóvedas descritas, además de no fijar las paredes que las sostienen, son muy sensibles a los movimientos que estas sufren, como también a los violentos golpes producidos por la caída de materiales desde lo alto.

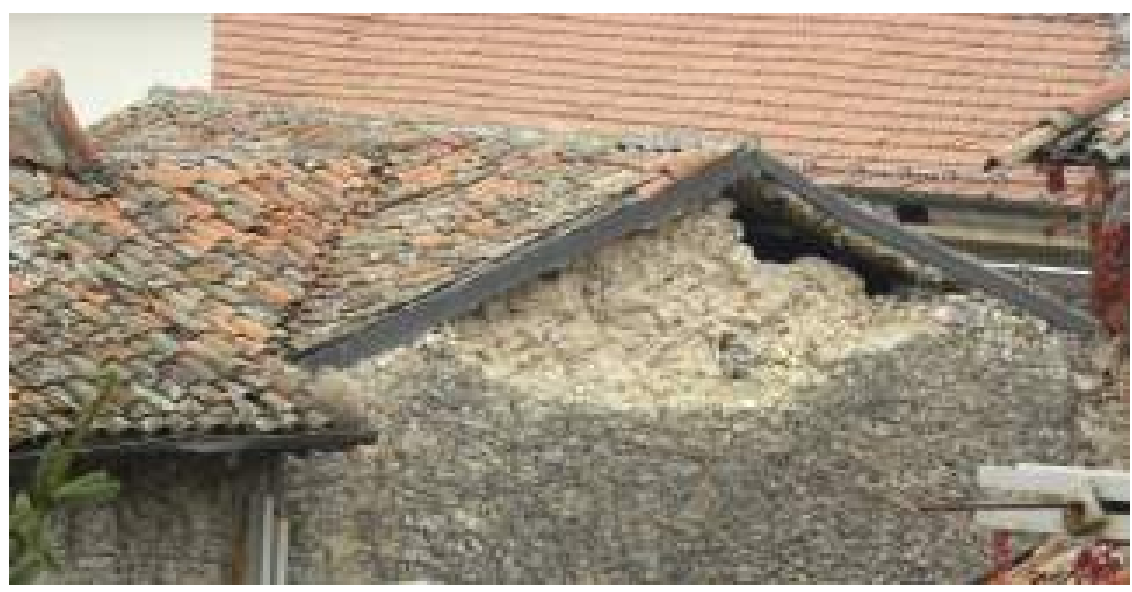

Figura 11.

En la figura 12 se ilustra un ejemplo de esta situación. Los estípites, que no están sujetos por la construcción del espacio y están poco o nada anclados a ella con llaves y clavos metálicos, han sido expulsados de su posición, arrastrando consigo los arquitrabes y los muros del cielorraso.

Se observa que muchos derrumbes directos, en el remate de las construcciones, han causado derrumbes indirectos por golpe sobre las estructuras de abajo. Sirve de ejemplo para todos, en la figura 9, la cobertura de la nave de la 


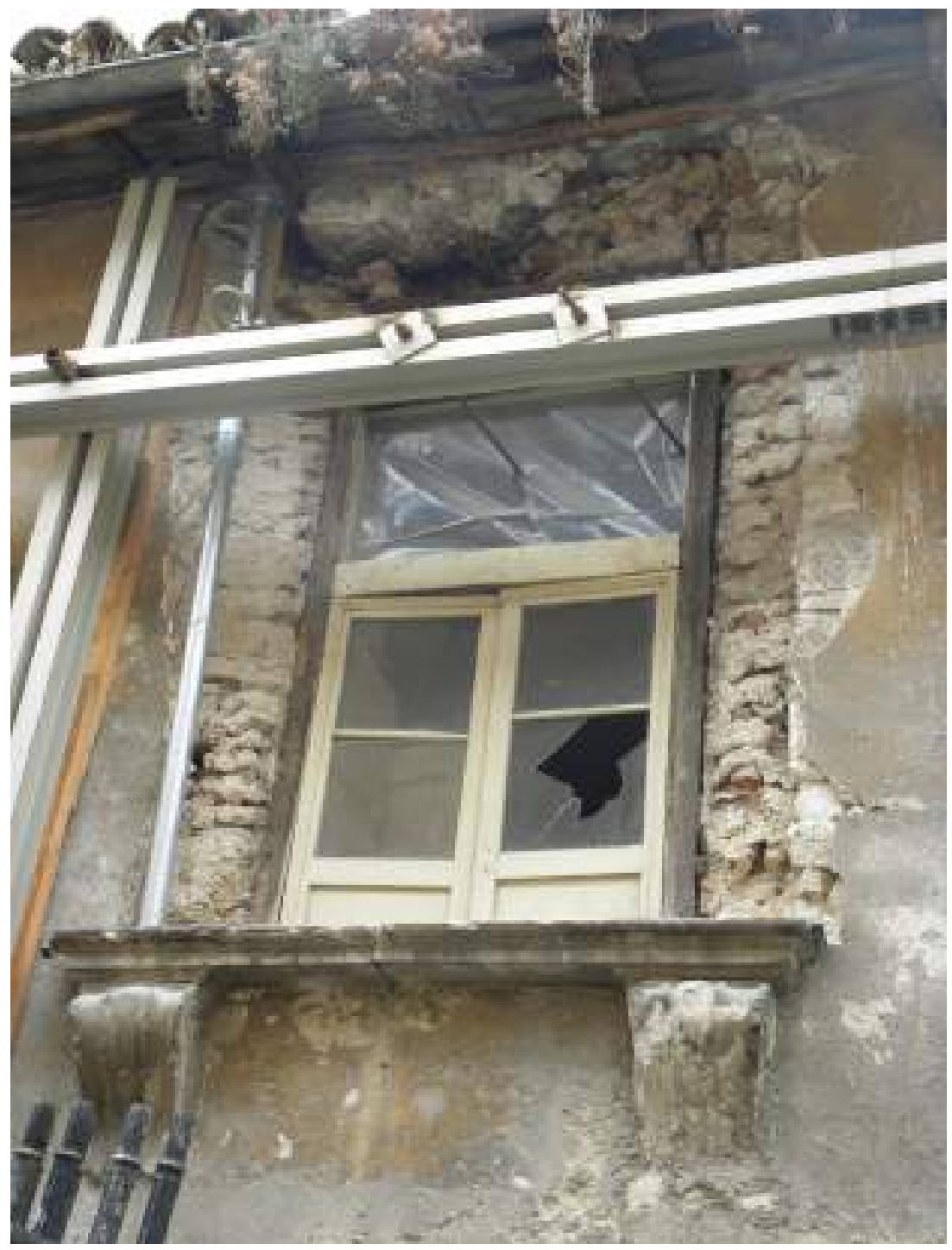

Figura 12. 
iglesia del Perpetuo Suffragio, localmente desplomada por la caída de parte del sistema tambor-cúpula de arriba. Por el contrario, donde más cuidada ha resultado la confección de las bóvedas en folio de ladrillos -con buen apoyo sobre las paredes y con disposición de cadenas retiene-empuje bien ancladas-, no se han manifestado los daños descritos. Análogamente, una confección cuidadosa de los remates de mampostería es la disposición en cadena de los cabestros de cobertura que han salvaguardado la integridad de las paredes de la fachada, localmente (en el remate) y en el conjunto (ausencia de movimientos de desplome). Para este último propósito, véase el detalle de la figura 13 más abajo. Enésima confirmación de la regola dell'arte.

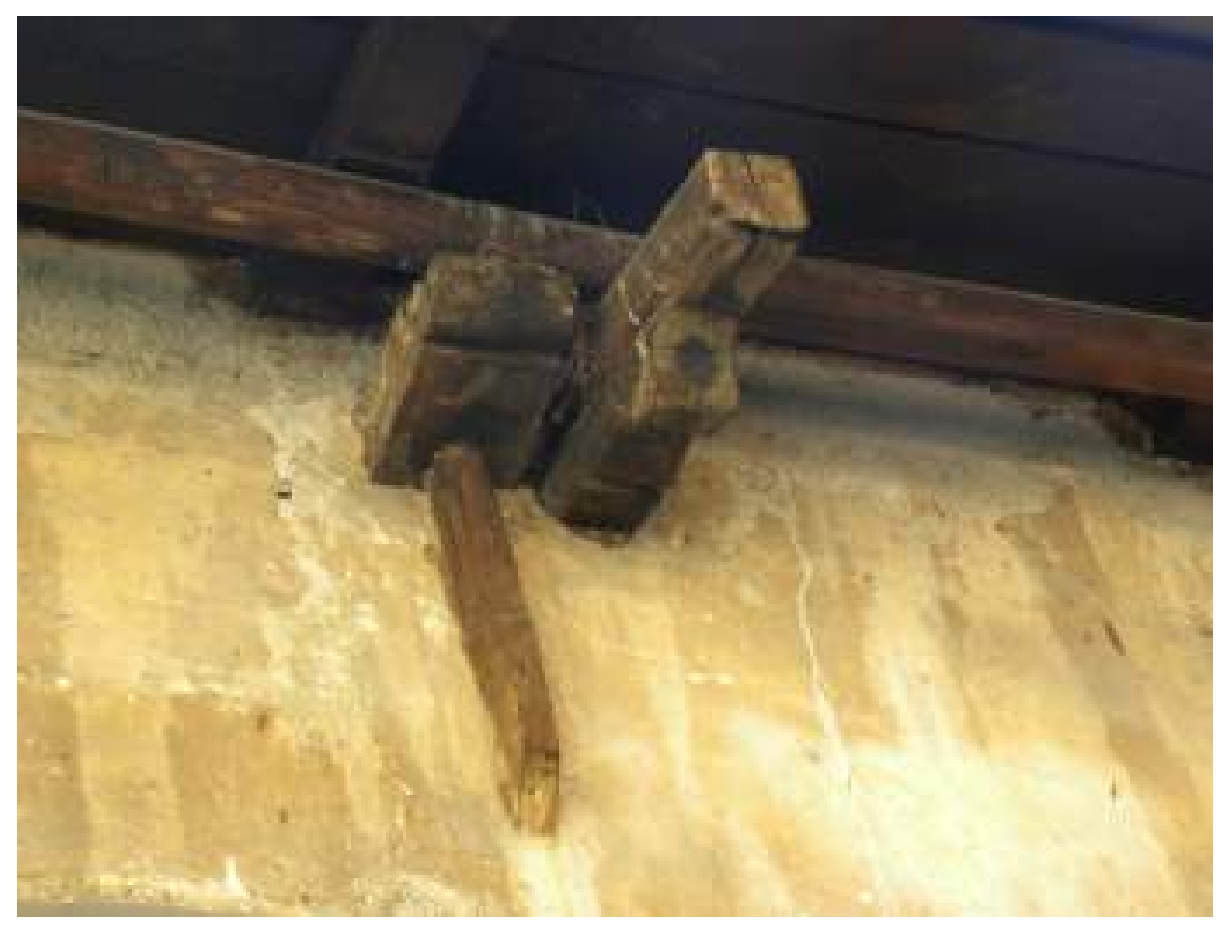

Figura 13. 
No aparecen, en general, desplazadas -sino por específicas causas de degradación o de alteración del tejido de construcción- las bóvedas de cobertura del piso semienterrado o del primer piso: son todavía una confirmación de las disposiciones de la construcción histórica. Las operaciones de consolidación de las construcciones -en los componentes estructurales y acoplativo-funcionales- se han iniciado desde 2013 con un articulado cuadro programático-económico que ha tenido también en cuenta las exigencias funcionales de los movimientos de maquinarias y medios de la obra al interior de un tejido vial angosto e irregular.

\section{CONFIABILIDAD DE LA OPERATIVIDAD DE LAS TÉCNICAS DE INTERVENCIÓN EN LA CONSTRUCCIÓN CON ESTRUCTURA DE MAMPOSTERÍA. LOS INSTRUMENTOS DE CONSOLIDACIÓN ANTISÍSMICA}

Se presentan las técnicas de intervención, encuadrándolas en el contexto de los objetivos individuales perseguidos.

1. Reducción de las acciones sísmicas

Se puede realizar efectuando:

1.1 la reducción de las masas, eliminando entonces las adiciones posteriores de la fabrica ${ }^{16}$, o sino reduciendo la cantidad de sobrecargas sobre los entrepisos y planos horizontales ${ }^{17}$;

1.2 la introducción de sistemas de amortiguación en los elementos estructurales;

1.3 la introducción de aisladores sísmicos en la base de la construcción.

2. Reorganización estructural

Se puede realizar efectuando:

16 Limitándose a los casos en los cuales no colisione con el significado histórico y artístico de la configuración "actual" de la construcción.

17 Por ejemplo, "desclasando" la destinación de uso hacia utilizaciones con menores cargas de ejercicio, aun si a menudo el ahorro que se obtiene de este modo no tiene un gran significado cuantitativo. 
2.1 el mejoramiento de las conexiones murales, disponiendo cadenas metálicas, mediante implantaciones murales tipo "cose-descose", con costuras armadas en los ángulos;

2.2 el mejoramiento de las conexiones entre paredes y entrepisos, mediante la inserción de cadenas metálicas, aplicación de tiras de fibra reforzada, ejecución de losas de concreto armado ancladas a los bordes con perforaciones armadas en las paredes;

2.3 la rigidización de los elementos en el plano horizontal, a modo de redistribuir las acciones sísmicas (de comportamiento por tiras a comportamiento global), como en el punto precedente;

2.4 la reducción entre los ejes de las paredes existentes mediante la inserción de nuevas paredes de mampostería, bien sujetas a las existentes;

2.5 la inserción de junturas técnicas, con redoble de paredes (suficientemente separadas entre sí).

3. Refuerzo de los elementos de construcción ${ }^{18}$

Se puede realizar efectuando:

3.1 el mejoramiento de las características mecánicas de la mampostería; por ejemplo, mediante la inyección de argamasas "tratadas", el sellado de las junturas en la parte mural a la vista, aplicando tiras de fibra reforzada;

3.2 la eliminación de discontinuidades locales, de hendiduras y de vacíos (chimeneas, puertas o ventanas muy juntas), efectuando rellenos del tipo "cose-descose", insertando telares metálicos entornillados a la mampostería, o revistiendo la pared con enlucido reforzado;

3.3 la reconstrucción de los remates de las paredes mediante vigas-collar reforzadas y bien ancladas verticalmente al cuerpo mural inferior;

18 Naturalmente, cuanto se ha indicado, que es específico de los elementos estructurales, vale también para los elementos de acabado y decorado que presentan las mismas necesidades de seguridad y conservación de la obra. 
3.4 la reconstrucción de las bases de las paredes, mediante la eliminación de vacíos existentes en el cuerpo de los cimientos, o mediante obras de sobrecimientos.

Con fines de ejemplificación, se presentan algunos casos particulares de la ejecución de la intervención 3.3, empleada para reforzar algunas construcciones del centro histórico de L'Aquila: figuras 15 y 16, en las páginas siguientes. Este tipo de refuerzo se adapta a mamposterías con piedras o ladrillos, con caras enlucidas o a la vista; en este último caso es frecuente encontrar la convivencia en el uso de piedras y ladrillos, como en la figura 14.

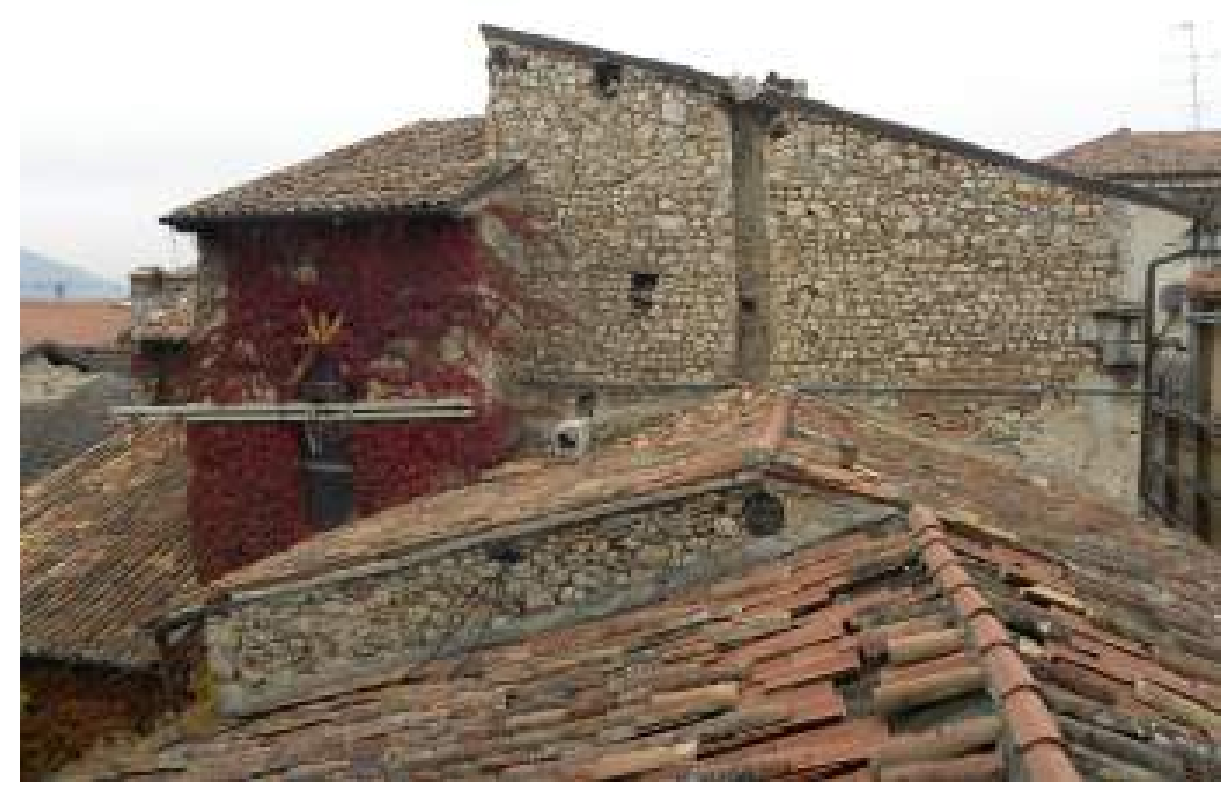

Figura 14. 


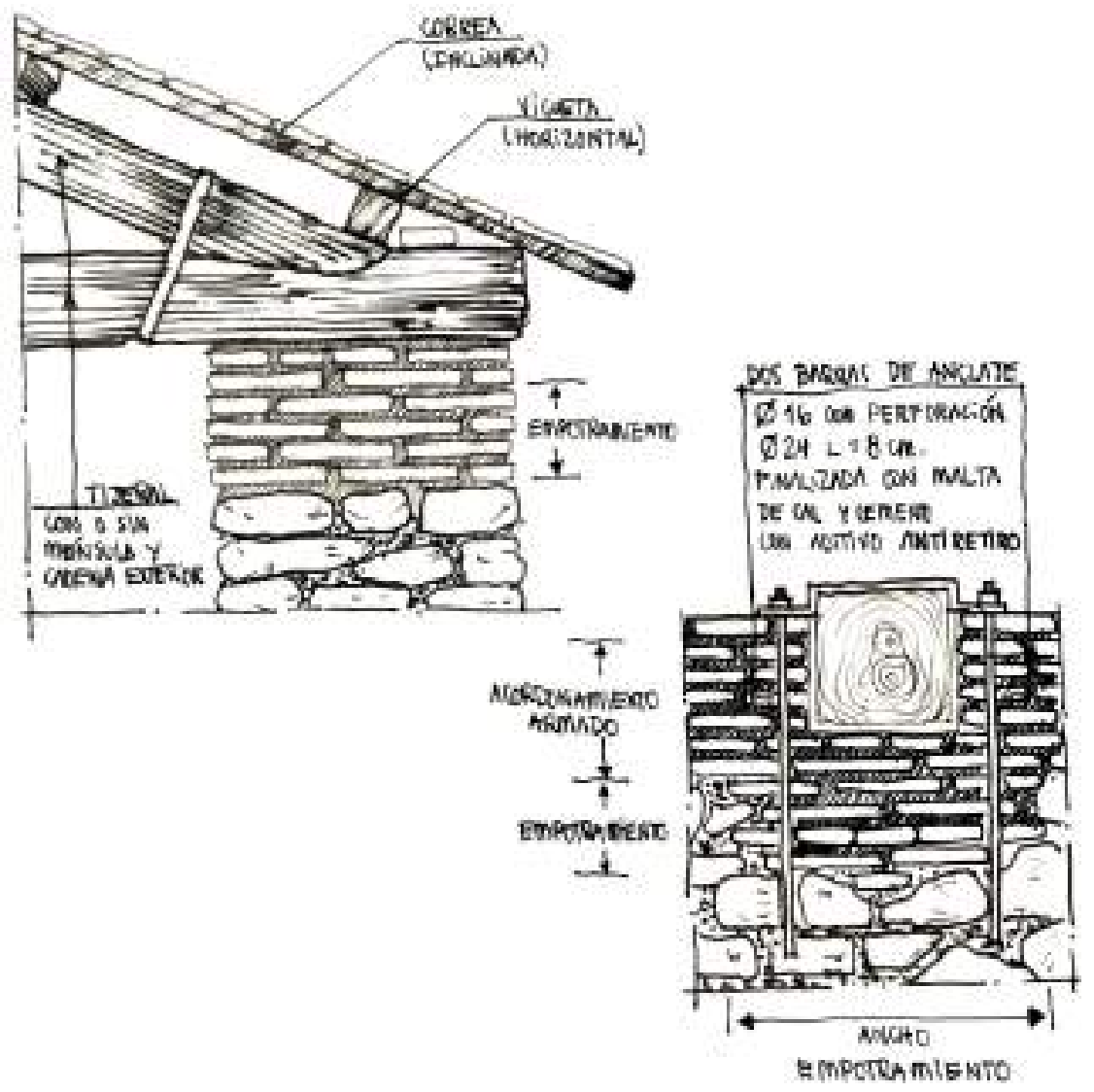

Figura 15.

Mejoramiento murario. Acordonamiento superior horizontal de las paredes de mampostería.

Desmontaje de las estructuras de madera de la cubierta (con sucesivo tratamiento de los elementos a reutilizar) y demolición de la cresta mural en piedra de la pared, por una altura de alrededor de 40 centímetros, con "engranajes" altos de $70 \mathrm{~cm}$ cada 1,5 m aproximadamente. La demolición es de espesor total o parcial, dependiendo de si la pared está estucada por ambos frentes o por un solo frente.

Construcción de un bordillo en mampostería de ladrillos de al menos seis filas, con diez filas en correspondencia con los "engranajes"; el extradós del bordillo contiene los encajes necesarios para la recolocación de las vigas de la cubierta.

Extensión, cada dos filas, de tiras de red de $10 \times 10 \mathrm{~cm}$ de extensión, seis milímetros de diámetro; perforación subvertical de $20 \mathrm{~mm}$ de diámetro cada $75 \mathrm{~cm}$, armadas con dos barras de $12 \mathrm{~mm}$ de diámetro a través del bordillo de $40 \mathrm{~cm}$ y la mampostería inferior por un largo total de 1,00 m. Las superposiciones de las tiras de red van efectuadas en correspondencia de una perforación.

Fuente: Francesco Piccarreta. Apunte: Abel del Pino 


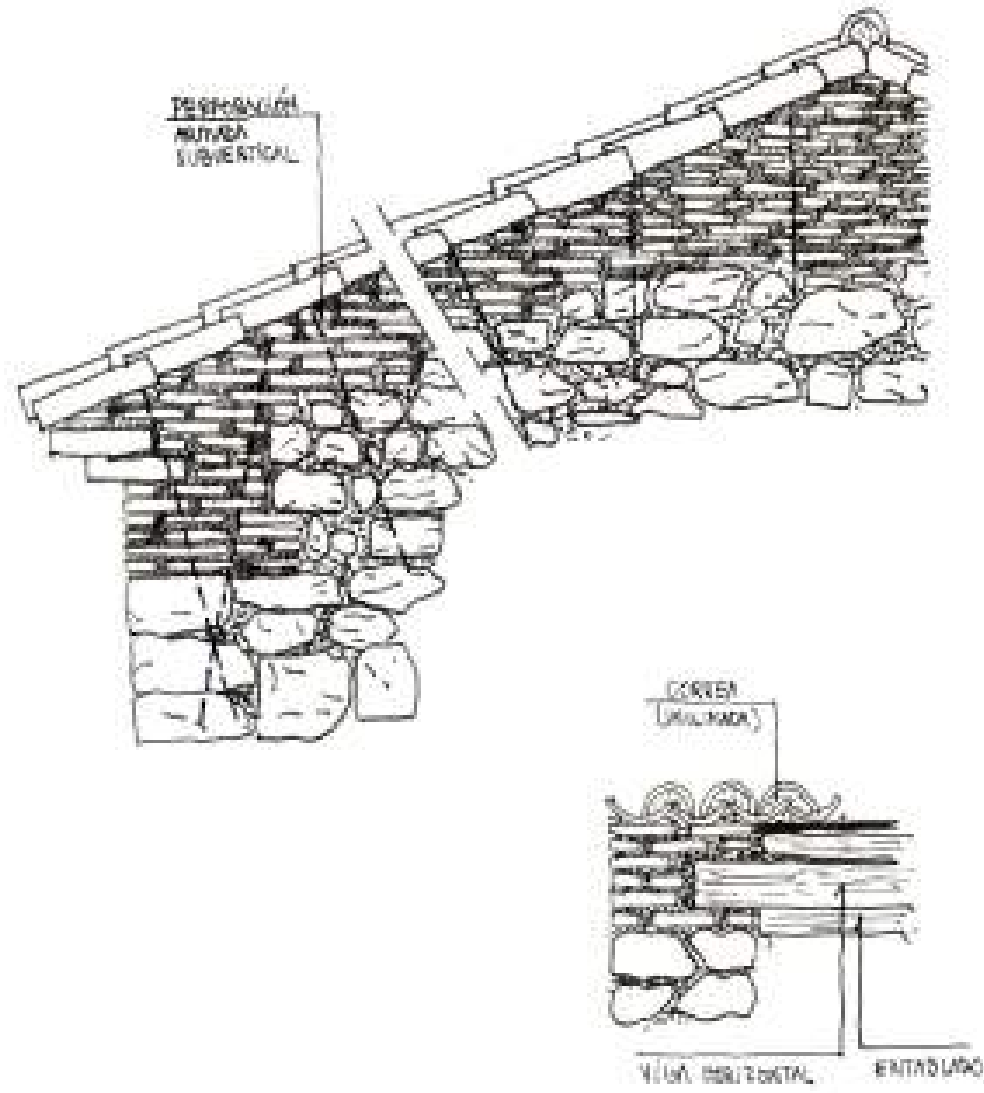

Figura 16.

Mejoramiento murario. Acordonamiento superior inclinado de las paredes de mampostería.

Desmontaje de las estructuras de madera de la cubierta (con sucesivo tratamiento de los elementos a reutilizar) y demolición de la cresta mural en piedra de la pared, por sucesivos "escalones" de una altura de alrededor de $40 \mathrm{~cm}$; la demolición del espesor es total o parcial, dependiendo de si la pared está estucada por ambos frentes o no.

Construcción de un bordillo en mampostería de ladrillos de al menos seis filas, con extradós que contiene los encajes necesarios para la recolocación de las vigas de la cubierta.

Extensión, cada dos filas, de tiras de red de $10 \times 10 \mathrm{~cm}$ de extensión, $6 \mathrm{~mm}$ de diámetro; perforación subvertical de $20 \mathrm{~mm}$ de diámetro cada $75 \mathrm{~cm}$, armadas con dos barras de $12 \mathrm{~mm}$ de diámetro a través del bordillo de $40 \mathrm{~cm}$ y la mampostería inferior por un largo total de 1,00 $\mathrm{m}$. Las superposiciones de las tiras de red van efectuadas en correspondencia de una perforación.

Fuente: Francesco Piccarreta. Apunte: Abel del Pino 
Las operaciones a las cuales recurrir van escogidas entre las posibles, en modo tal de satisfacer una serie de requisitos casi sintetizables: confiabilidad, reversibilidad ${ }^{19}$, duración, necesidad ${ }^{20}$, mínima intervención. Desde este punto de vista, se privilegian las técnicas de la tradición constructiva ciertamente confiable -ampliamente experimentadas, poco invasivas y homogéneas con la construcción histórica-, como bases de muestra, inserción de cadenas, reestructuraciones locales tipo "cose-descose", inserción de espuelas murales o nuevas paredes, etc. Aunque menos homogéneas con la construcción, también podemos considerar intervenciones llamadas modernas -es decir que se remontan a las primeras décadas del siglo pasado-, como una base de cimientos con micropalos, inyecciones de argamasa, costuras armadas, recubrimientos con plantillas armadas o enlucido armado, etc.

Menos experimentadas, en cuanto han sido introducidas solamente en la última década del siglo pasado, resultan las técnicas innovadoras (tiras de fibra reforzada, inyecciones de resinas, aleaciones "con memoria de forma" ${ }^{21}$, aislamiento sísmico, etc.), que no presentan igualmente una amplia experimentación en acción. El aislamiento sísmico en la base de la construcción -que actúa con un aumento considerable del período propio de la construcción originaria, y por lo tanto llevando la construcción fuera del campo de amplificación de los efectos del sismo, típico de los bajos

19 Entendida como posibilidad de una operación a ser sustituida por otra en la función desenvuelta (que se haya demostrado, por ejemplo, más eficaz; 0 que sea necesaria para completar una intervención más amplia, que se ha vuelto necesaria por eventos presentados en tiempos sucesivos, o a ser sustituida por mal desempeño de la anterior). Es ejemplo de la última motivación el cuidadoso trabajo de sustitución de los remiendos armados realizados, en la década de 1990, en los tejidos murales de un edificio sacro de la ciudad de Lecce; las barras de acero utilizadas, en marcado estado de corrosión -con el riesgo de dañar la delicada piedra de Lecce, por efectos de la hinchazón o de manchas de óxido sobre el paramento externo-, están en curso de sustitución con barras de acero inoxidable mediante operaciones de reperforación coaxial, en correspondencia con las barras originales, a cambiar y sustituir por barras de acero inoxidable.

20 Contra intervenciones excesivamente redundantes.

21 La aleación con memoria de forma (Shape Memory Alloys, SMA), producida en barras metálicas, se caracteriza por la llamada superelasticidad: un regreso a cero, con la tensión de la deformación según un ciclo parcial de carga y descarga. Se observa que el retorno a cero de la deformación ocurre según un ciclo, y por tanto con (ligera) absorción de energía. 
períodos propios- presenta la indudable ventaja de no tener necesariamente que intervenir sobre el elevado, de hecho vuelto "insensible" al sismo, sin alterar -sea al menos en el respeto de los requisitos antes nombrados- las características constructivas, históricas, artísticas. Más bien, esta técnica parece aplicable en el caso de construcciones "compactas" (por ejemplo, campanarios, torres, etc.) pero de dificil aplicación para construcciones sobre áreas extensas y articuladas altimétricamente.

En realidad, una cierta "puesta a prueba" de estas técnicas innovadoras ya se ha tenido, con la reiteración de manifestaciones sísmicas en las localidades sometidas a intervenciones de consolidación; "puesta a prueba" que por otro lado ha tenido también resultados negativos, pues ha evidenciado intervenciones erradas o no conformes con las expectativas (en verdad, más por superficialidad de la ejecución que por la inherente deficiencia).Así, por ejemplo, se ha revelado el empleo del enlucido reforzado efectuado -sobre paredes de gran espesor- con redes metálicas de mínimo diámetro, poco ancladas a los muros posteriores y con delgado recubrimiento de enlucido. O la reestructuración, con estructuras de cemento armado, de coberturas y altillos sin acompañamiento de una conveniente mejora de los muros inferiores. O también la escasa eficiencia de las inyecciones de resina, sin el adecuado recubrimiento protector contra los agentes atmosféricos.

En definitiva, la elección organizativa -en calidad, cantidad, coordinación de los efectos producidos- de las intervenciones antes descritas, para definir el específico proyecto de consolidación, debería empezar del ya recordado estudio orgánico de la construcción sobre la cual intervenir y del reconocimiento de sus necesidades en relación con las características de la construcción según la regla del arte. No parece que actualmente se esté procediendo de este modo, y con frecuencia se encuentra una "somera" aquiescencia, por parte del proyectista, a las técnicas "de moda", de particular conveniencia para la empresa ejecutora de los trabajos. Se observa, por ejemplo, un excesivo recurso de las técnicas de aplicación de tiras de fibra reforzada (a menudo, en la variante de cables de acero): aplicadas en retícula - previo retiro del enlucido- sobre ambas caras de cada pared, que están conectadas entre ellas por costuras transversales localizadas en los cruces de las tiras; estas costuras pasan dentro de perforaciones en el cuerpo mural, "enlazándose" en los extremos, encoladas a las tiras de la pared. 
Además de haber sacrificado el entero enlucido y eventuales decoraciones, el tejido mural de las paredes - que también ha dado buena prueba de sí mismo, no habiendo padecido daños graves o derrumbes- ha sido establemente enjaulado en una prótesis de contención. Más que para empleos generalizados del tipo descrito, esta técnica debería ser en cambio observada para empleos localizados, para exigencias específicas (por ejemplo, el refuerzo del extradós de una cúpula de altillo en la corteza de ladrillos llenos, si se quiere trabajar sin aumento de peso; el refuerzo de paredes a la altura de un piso, con altillo de madera para mantener en la obra; el refuerzo local de estructuras de madera, etc.).

\section{MÉTODOS DE ANÁLISIS ESTRUCTURAL}

Si los entrepisos, como frecuentemente sucede en los edificios históricos, no presentan ni una solidez confiable ni una significativa rigidez del propio plano (horizontal), cada una de las $n$ paredes resistentes longitudinalmente se comporta independientemente de las otras $n-1$, soportando la "carga sísmica" de exclusiva competencia y cumpliendo movimientos horizontales no correlacionados con los correspondientes movimientos de las otras paredes longitudinales.

$\mathrm{Si}$, viceversa, los entrepisos resultan monolíticos y presentan una fuerte rigidez en el propio plano, el comportamiento de las paredes está vinculado al respeto de la congruencia con la (casi) indeformabilidad de los altillos en los respectivos planos medios. En particular, para altillos tan poco deformables que pueden ser considerados rígidos, todas las paredes cumplen movimientos horizontales iguales ${ }^{22}$ y la acción sísmica en conjunto viene distribuida entre las varias paredes longitudinales sobre la base de la correspondiente rigidez.

Se determinan, por lo tanto, dos modalidades de análisis estructural.

1) Comportamiento en tiras.- Cada pared longitudinal debe soportar las acciones sísmicas correspondientes a los pesos de todos los elementos de

22 Si la planimetría de la construcción presenta un eje de simetría estructural Iongitudinal (el baricentro de las masas coincidente con el baricentro de las rigideces), por lo cual el único movimiento de conjunto posible en cada plano es el de translación. De otra forma, es necesario tener en cuenta las excentricidades entre los dos baricentros mencionados. 
construcción comprendidos en el volumen de competencia, determinado entre los ejes de las paredes longitudinales adyacentes, que proporcionan la resistencia exclusivamente -en una suerte de "federalismo antisísmico"con las propias potencialidades. Las paredes transversales, especialmente, deben resultar eficazmente ancladas a las otras -sea a través del amarre de los ángulos, sea a través de las conexiones con los altillos, sea, incluso, por medio de ulteriores procedimientos- en modo de no determinar cinematismos de volcadura y no sufrir daños por efecto de los distintos movimientos horizontales de las paredes que las sostienen.

Análogamente, los altillos no deben sufrir desprendimientos por efecto de los distintos movimientos de las paredes entre las cuales están puestos. Esta situación es representativa de las construcciones en el estado actual (o sea, en su estado original). La crisis está determinada por el colapso de agotamiento de la pared más solicitada.

2) Comportamiento global.- Las n paredes longitudinales colaboran entre sí, interviniendo en el soporte de la acción sísmica de conjunto -correspondiente al peso total de la construcción- inicialmente en proporción a la propia rigidez (elástica). Al crecer la acción sísmica, una (o más) de ellas puede sufrir eventualmente un bloqueo en la resistencia cuando se alcanza el umbral de ductilidad: desde este momento la pared continúa deformándose sin aumento de la resistencia y son las $n-1$ paredes restantes las que absorben posteriores aumentos de la acción misma, con eventuales agotamientos de ductilidad de otras paredes. Las paredes transversales deben resultar siempre eficazmente ancladas a las otras, para no determinar cinematismos de volcadura; los entrepisos deben conservar compactibilidad, rigidez y conexiones a las paredes longitudinales. Esta situación es representativa de las construcciones en el estado futuro (o sea, en su estado consolidado). La crisis está determinada por el colapso de una o más paredes que han agotado su ductilidad.

Una evaluación de primera aproximación del peso en conjunto de la construcción en estudio -incluyendo las sobrecargas- puede ser hecha mediante la fórmula:

$$
\mathrm{W}=\Gamma_{\text {app }} \mathrm{V}
$$


donde:

V es el volumen ocupado por la construcción (vacío por lleno),

$\Gamma_{\text {app }}$ es el peso correspondiente por unidad de volumen,

a ser asumido como par a:

$300 / 400 \mathrm{~kg} / \mathrm{m}^{3}$ para edificios de cemento armado;

$550 / 650 \mathrm{~kg} / \mathrm{m}^{3}$ para edificios de mampostería.

Las variaciones de los valores indicados pueden ser debidas a las distintas entidades de las sobrecargas y a las diferentes consistencias de los entrepisos (edificios de mampostería) o de las paredes perimetrales (edificios de cemento armado).

En el comportamiento de las tiras se pueden considerar los volúmenes aferentes de las tiras individuales, en número $n$ par a las paredes dispuestas según la considerada dirección longitudinal.

Resulta así:Wi $=\wp_{\text {app }} \mathrm{Wi}$,

siendo $\mathrm{Vi}=\mathrm{V}$ con $\mathrm{i}=1,2, \ldots, \mathrm{n}$.

Por lo que respecta a la acción sísmica del proyecto, la normativa antisísmica ofrece el valor, correlacionado a varios factores: desde la peligrosidad sísmica de la zona hasta las características del suelo. Comprensivamente, las acciones del proyecto pueden ser expresadas de la forma $\mathrm{F}=\varnothing \mathrm{W}$, en que el coeficiente $\varnothing$ depende de los parámetros arriba indicados (se puede asumir valores comprendidos entre 2,5 y 3,5$)$. El comportamiento de las paredes está referido al último estado, de volcadura y de desplazamiento, respectivamente, para los dos órdenes de paredes. El cálculo de la fuerza sísmica horizontal es inmediato, siguiendo el criterio "expeditivo" indicado para la valoración del peso (para la entera construcción o para porciones individuales de esta). La fuerza horizontal de colapso es la fuerza $F_{u}$ definida precedentemente. 
Tomando en cuenta cuanto se ha expuesto, un primer examen de las actitudes antisísmicas ${ }^{23}$ de una construcción existente tendrá que "pasar" por las propiedades ya indicadas (una suerte de primera "parrilla" de control).

- "Suficiente presencia" de paredes paralelas, para cada una de las dos direcciones, longitudinal y transversal (ladeadas y no necesariamente perpendiculares entre ellas), en número, espesor, distancia, "aberturas", equipos de construcción.

- Buena consistencia de los entrepisos, que deben resultar bien implantados en las paredes y desprovistos de empuje.

- Buenas conexiones de las paredes entre sí (amarres murales).

- En la eventual presencia de cadenas, se necesita controlar el estado de conservación y la capacidad de tiro, una correcta presencia de elementos de contraste a la mampostería (llaves, paletas, ganchos), desconfiando de las terminaciones que desaparecen en la mampostería.

La posesión de las cualidades arriba mencionadas constituye en sí misma un buen índice de la actitud antisísmica, a confirmar luego mediante las verificaciones de primera aproximación arriba especificadas. El examen conducido de esta forma puede llevar a la definición del cuadro de operaciones de intervención para el refuerzo preventivo ${ }^{24}$ de la edificación, como también para los refuerzos postsísmicos, que se deben efectuar-como resulta en general posible- actuando según una (o más) de las modalidades anteriormente examinadas.

Para la construcción bajo examen se concluye, por tanto, con la definición dentro del cuadro general de intervención, el estudio de calificación según la regla del arte y el reconocimiento de la actitud antisísmica. Es entonces en esta fase que se podrá afrontar la definición numérica de la seguridad, o sea

23 Actitud y confiabilidad antisísmica (atributo positivo) en lugar de vulnerabilidad sísmica (atributo negativo) de las construcciones.

24 La normativa italiana nos obliga en general a realizar prevenciones antisísmicas, provistas en cambio de casos específicos de modificación del organismo de la construcción originaria (mejoramiento, o sino adecuación antisísmica). 
la correspondencia a las disposiciones de la normativa: realizada con el uso de métodos -estáticos o dinámicos, lineales o no lineales- y programas de cálculo del moderno análisis estructural.Procedimientos en sí mismos siempre tan estimados por los ingenieros proyectistas y los funcionarios encargados de la aprobación de los proyectos, como se mencionó anteriormente, pero que ahora -realizados al término del estudio aquí descrito- resultan ciertamente confiables (no solo en términos de resultados numéricos, sino también en relación con una elección adecuada, en cantidad y calidad, de las intervenciones a realizar) por ser derivados de datos apropiados de ingreso y en conjunto confrontables, en cuanto a los resultados obtenidos, con los resultados del estudio descrito. 